\title{
RNA Fragmentation in MALDI Mass \\ Spectrometry Studied by H/D-Exchange: \\ Mechanisms of General Applicability \\ to Nucleic Acids
}

\author{
Thomas E. Andersen* and Finn Kirpekar \\ Department of Biochemistry and Molecular Biology, University of Southern Denmark, Odense, Denmark
}

\author{
Kim F. Haselmann
}

Department of Chemistry, University of Southern Denmark, Odense, Denmark

\begin{abstract}
To reveal the gas-phase chemistry of RNA and DNA fragmentation during MALDI mass spectrometry in positive ion mode, we performed hydrogen/deuterium exchange on a series of RNA and DNA tetranucleotides and studied their fragmentation patterns on a highresolution MALDI TOF-TOF instrument. We were specifically interested in elucidating the remarkably different fragmentation behavior of RNA and DNA, i.e., the characteristic and abundant production of c- and y-ions from RNA versus a dominating generation of (a-B)- and w-ions from DNA analytes. The analysis yielded important information on all significant backbone cleavages as well as nucleobase losses. Based on this, we suggest common fragmentation mechanisms for RNA and DNA as well as an important RNA-specific reaction requiring a 2'-hydroxyl group, leading to c- and y-ions. The data is viewed and discussed in the context of previously published data to obtain a coherent picture of the fragmentation of singly protonated nucleic acids. (J Am Soc Mass Spectrom 2006, 17, 1353-1368) (C) 2006 American Society for Mass Spectrometry
\end{abstract}

$\mathrm{T}$ The gas-phase fragmentation of oligonucleotides has been studied during the past two decades, beginning with the early fast-atom bombardment studies by Grotjahn et al. [1, 2]. Introduction of the soft ionization methods electrospray ionization (ESI) and matrix assisted laser desorption/ionization (MALDI) in the early 90s increased the general emphasis on developing mass spectrometry for oligonucleotide research. An extensive effort has since then been made to uncover the mechanisms of gas-phase fragmentation, particularly of DNA, to cope with uncontrolled fragmentation and to develop sequencing and analysis strategies by tandem mass spectrometry. A comprehensive review of the research in this field was recently published by $\mathrm{Wu}$ and McLuckey [3]. Here, it was concluded that albeit several reactions that have been proposed, no single mechanism is able to fully account for the reported data. The discrepant data previously published in this field leaves a somewhat turbid picture of oligonucleotide gas-phase fragmentation. It is therefore evident

Published online July 27, 2006

Address reprint requests to Dr. F. Kirpekar, Department of Biochemistry and Molecular Biology, University of Southern Denmark, Campusvej 55, 5230 Odense M, Denmark. E-mail: f.kir@bmb.sdu.dk

*Current address: Nanon A/S, Priorparken 878, DK-2605 Brøndby, Denmark. that more research is needed to clarify and fully understand the chemistry of oligonucleotides in mass spectrometry.

Fragmentation analysis using hydrogen/deuterium exchange (H/DX) was initially employed by Phillips and McCloskey on dinucleoside monophosphates [4]. Later, the method was utilized by the groups of Franz Hillenkamp and Michael Gross for fragmentation analysis of oligonucleotides [5-7]. This method is perhaps the only one available, which can provide a direct evidence for a fragmentation mechanism. Based on the H/DX data [5-7], it has been proposed that every fragmentation events of DNA, except losses of water and of $3^{\prime}$ - and $5^{\prime}$ - terminal nucleoside/nucleotides, is initiated by loss of a nucleobase. Several mechanisms for the subsequent $3^{\prime}-\mathrm{C}-\mathrm{O}$ cleavage and production of DNA-characteristic w/a-B fragment ions [8] have been proposed (important ones are described briefly by Wan et al. [6] and comprehensively by $\mathrm{Wu}$ and McLuckey [3]). The H/DX data tend to support a mechanism involving formation of a zwitterionic species, first proposed by Wang et al. [9].

The large-volume of literature on DNA fragmentation is in sharp contrast to the very limited number of publications on RNA fragmentation. Kirpekar and Krogh [10] studied the CID of various positively 
charged RNA-oligonucleotides using a MALDI-QqTOF instrument. They reported a strong preference for $5^{\prime}$ $\mathrm{P}-\mathrm{O}$ cleavage, yielding prevalent $\mathrm{c} / \mathrm{y}$ sequence-ions, what was later also observed for negative, ESI-generated RNA-ions by Schürch et al. [11]. These authors suggested a $5^{\prime}-\mathrm{P}-\mathrm{O}$ cleavage mechanism involving the bridging of the $2^{\prime}-\mathrm{OH}$ proton to $5^{\prime}-\mathrm{PO}$ oxygen. In a recent study of the fragmentation of doubly deprotonated RNA tetramers, Tromp and Schürch [12] found that a $5^{\prime}-\mathrm{P}-\mathrm{O}$ bond was cleaved to a similar extend in absence of a $3^{\prime}$-adjacent nucleobase (replaced by hydrogen). They concluded that the nucleobase did not play a key role in $5^{\prime}-\mathrm{P}-\mathrm{O}$ cleavage. No dedicated studies exist regarding the fragmentation mechanism of $5^{\prime}$ $\mathrm{P}-\mathrm{O}$ cleavage of positively charged oligonucleotides, and no comparative survey has so far been conducted to explain the significant differences in fragmentation behavior of RNA and DNA.

In the current study, we investigated the fragmentation mechanisms of RNA and DNA by H/DX and high-resolution MALDI TOF tandem mass spectrometry. N-glycosidic bond and all backbone cleavages have been analyzed and all but $3^{\prime} \mathrm{P}-\mathrm{O}$ cleavage yielding the $\mathrm{b} / \mathrm{x}$-ions are described, because these ions were generally insignificant in both the RNA and DNA MS/MS spectra. We report data, which partly confirm and extend the previously proposed fragmentation mechanisms of DNA. Based on the RNA H/DX data we propose an important dissociation reaction specific for this analyte, and rationalize the different RNA and DNA fragmentation behavior.

\section{Experimental}

\section{Instrumentation}

Positive ion spectra in the MS and MS/MS mode were recorded on a 4700 Proteomics Analyzer (Applied Biosystems, Framingham, MA) equipped with a $200-\mathrm{Hz}$ Nd:YAG laser operating at a wavelength of $355 \mathrm{~nm}$. MS-spectra were recorded in the reflectron mode $(20 \mathrm{kV}$ accelerating voltage), with 380-400 ns delayed extraction. MS/MS-spectra were recorded in the CID mode, the accelerating voltage was $8 \mathrm{kV}$ and the collision energy $1 \mathrm{keV}$. Argon was used as collision gas in the MALDI TOF-TOF instrument, at an indicated manifold pressure of $\sim 1 \times 10^{-6}$ torr.

\section{Sample Preparation}

To achieve a $>98 \%$ deuteration level for the mass spectral recordings, all sample preparation were carried out in a glove-bag (Sigma-Aldrich, Vallensbaek Strand, Denmark) connected to the loading mount of the mass spectrometer. This facilitated deuteration and loading of the samples without any contact with atmospheric moist. Nitrogen was used to flush the glove-bag and to vent the pre-chamber in a closed system with only an opening through a valve connection to the vacuum pump. To obtain close to $100 \%$ nitrogen in the glovebag, it was inflated and evacuated sequentially several times before the deuteration procedure. The RNA tetramers (UUUU, UCUU, UAUU, UGUU, AUCU, UCUA, UAUC, UGUC, and a 2'-methylated UmA$\mathrm{mUmCm}$ ) were purchased from Dharmacon (Lafayette, CO), DNA tetramers (TATT, TCTT, TCTA, TATC, TATG) from DNA technology A/S (Aarhus, Denmark), and nucleosides from Sigma-Aldrich. The THAP-matrix was a 4:2:1-mixture of 0.2 M 2,4,6-trihydroxyacetophe-

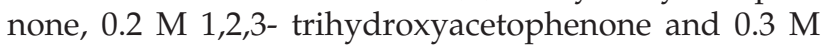
diammonium citrate (Sigma-Aldrich) dissolved in 1:1 deionized $\mathrm{H}_{2} \mathrm{O}$ and acetonitrile (Fisher Chemicals, $\mathrm{Zu}-$ rich, Switzerland $99.99 \%$ pure) or deuterium oxide $\left(\mathrm{D}_{2} \mathrm{O}\right.$; Merck, Darmstadt, Germany $99.95 \%$ pure) and acetonitrile. The deuterated matrix was vacuum-dried and redissolved in $\mathrm{D}_{2} \mathrm{O}$ /acetonitrile three times before entering the glove-bag; $100-200 \mathrm{pmol}$ of DNA/RNA or $500 \mathrm{pmol}$ of nucleoside were deuterated in the glovebag by dissolving in $4 \mu 1 \mathrm{D}_{2} \mathrm{O}$ on-target, and drying in an exsiccator. This procedure was repeated three times. One $\mu \mathrm{l}$ predeuterated matrix was mixed and crystallized with the sample before analysis.

\section{Data Acquisition and Analysis}

Before tandem mass spectrometry, samples were checked in the MS-mode for purity and precursor ion signal, and deuterated precursors were checked for $>98 \%$ deuteration level. The window for precursor ion selection in the MS/MS-mode was set to $\pm 5 \mathrm{~m} / \mathrm{z}$ values. An MS/MS-spectrum was a sum of $\sim 30$ single-spectra, each of which originated from 110 single laser-shots. The spectra were subsequently analyzed and calibrated using the Data Explorer version 4.5 software Applied Biosystems, supplied by the manufacturer. For calculation of native and deuterated fragment masses, the nuke-software was utilized (Leisner, A., Institute for Medical Physics and Biophysics, University of Münster, Germany, http://www.zebra-crossing.de/software/ index.html) or the ChemSketch freeware (ACD).

\section{Results and Discussion}

Several previous H/DX-MS studies of DNA fragmentation have been conducted on nucleotide tetramers with one or two high proton affinity (PA) bases (adenine, guanine, and cytosine) in a low PA base (thymine) environment $[5-7,13]$. To obtain comparable dataset, DNA tetramers of similar compositions were analyzed. For RNA, tetramers with high PA base(s) in a uracil environment were analyzed. Backbone fragmentation data of uracil oligoribonucleotides containing cytosine are not very informative since the mass of $H / D$ exchanged cytosine equals that of $\mathrm{H} / \mathrm{D}$-exchanged uracil. Fragmentation data from such a tetramer (UCUU) was evaluated, but only for neutral or charged cytosine loss, which could be assumed since uracil is rarely lost 

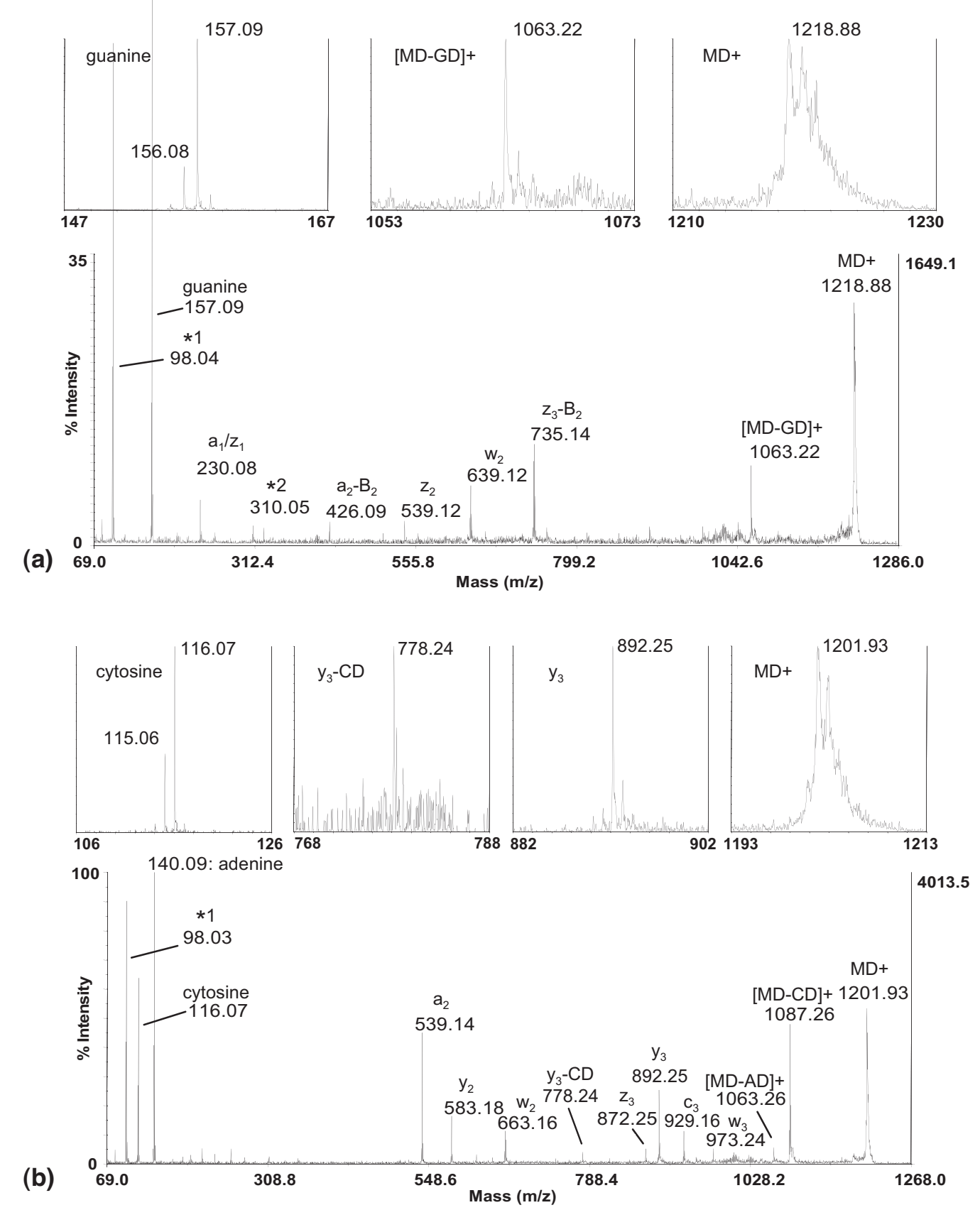

Figure 1. Tandem mass spectra of H/D-exchanged UGUU (a) and UCUA (b), with important regions enlarged above each spectrum. The UGUU spectrum is cut to $35 \%$ intensity of the base peak (guanine). The precursor ions (UGUU: $m / z 1218.88$ and UCUA: $m / z$ 1201.93) show the high degree of deuteration required to perform the H/DX MS/MS analysis. When a signal is split into more than one peak, the most intense is assigned. (asterisk)*1: ribose derivate; (asterisk)*2: internal fragment containing uracil.

in the fragmentation process. The current fragmentation study was based on CID MS/MS spectra, and it could be argued that these data are not comparable to previously published MALDI PSD data. We did, however, perform a rigorous comparison of the fragmentation of $\mathrm{H} / \mathrm{D}$-exchanged oligonucleotides in the CID and PSDonly mode (data not shown). The data were qualitatively identical in these two modes, which strongly suggest that identical fragmentation mechanisms operate. The only difference was an increased signal from low-mass fragments in the CID mode. In accordance with previous studies employing H/DX-MS in oligonucleotide fragmentation analysis (e.g., [5], we do not have any indications that the H/DX affects the fragmentation characteristics of the oligonucleotide: except for the peak splitting characteristic for the fragmenta- 


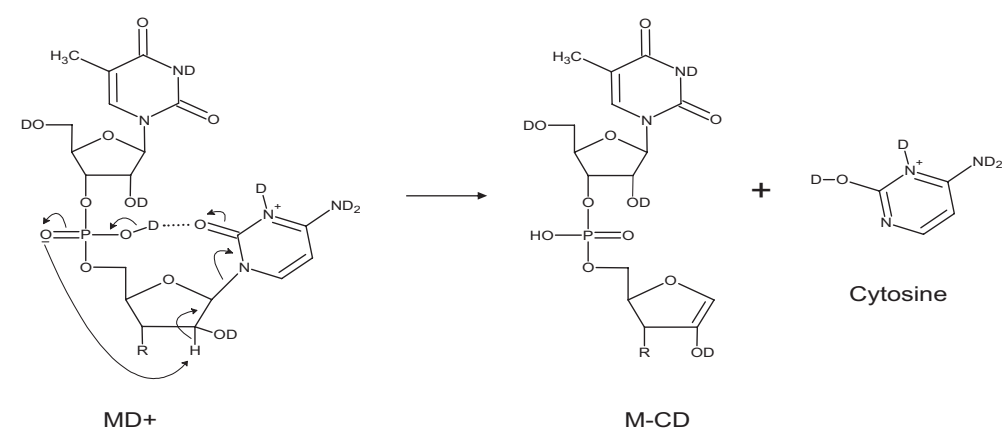

Scheme 1. Proposed fragmentation mechanism of formation of a charged nucleobase, here cytosine, from an RNA precursor. A possible hydrogen bond is indicated between cytosine and the nearby phosphate.

tion of $\mathrm{H} / \mathrm{D}$-exchanged precursors, no differences in the fragmentation pattern of the deuterated versus the native species were observed.

Figure 1 shows full tandem mass spectra of deuterated UGUU and UCUA. Some interesting regions are enlarged and displayed above each spectrum. The iongating for precursor selection in MS/MS mode distorts and offsets the precursor ion signal somewhat $(\sim 0.6 \mathrm{~m} / \mathrm{z}$ values). However, the enlarged precursor ion signals clearly show that a deuteration level very close to $100 \%$ is reached.

\section{Cleavage of the N-Glycosidic Bond}

Fragmentation of the H/D-exchanged RNA tetramers yielded information on the mechanism of N-glycosidic bond cleavage. The peak at $\mathrm{m} / \mathrm{z} 1063.22$ in Figure 1a corresponds to loss of neutral guanine from the UGUU tetramer. The mass difference of $155 \mathrm{Da}$ compared to the intact precursor indicates that guanine departs as a completely exchanged (hereafter c.e.) species, i.e., with all four exchangeable sites occupied by deuterons. Loss of a neutral nucleobase as a fully deuterated species was observed consistently for all RNA tetramers, a result which is similar to that previously reported for DNA by Gross et al. [5]. They suggested a mechanism of nucleobase loss in which the nucleobase leaves with the excess proton (deuteron). Our results show that neutral nucleobase loss from RNA takes place in a similar way.

A crucial point here is that upon departure of a fully deuterated neutral nucleobase, the hydrogens in the remaining ion rearrange in a way that inevitably transfers a nonmobile proton to a mobile site. Thus, one hydrogen becomes mobile and intramolecular H/DX in the gas phase is now possible [5]. Although the rates of such intramolecular H/DX in the gas phase have not been assessed in any previous study, our results strongly indicate that this rate is much higher than the time required for subsequent backbone fragmentation events (i.e., $100 \%$ scrambling will occur). This is based on our interpretation of the significant amount of data analyzed in the current study, which simply cannot be explained otherwise. We furthermore refer to a recent study performed on the same instrument, which clearly shows $100 \%$ scrambling for peptides in the gas phase upon tandem MS [14].

The upper left spectra in Figure $1 \mathrm{a}$ and $\mathrm{b}$ show enlargements of the signals corresponding to charged guanine and cytosine, from an UGUU and an UCUA precursor, respectively. These spectra demonstrate that the charged nucleobases are predominated by c.e. species. Hence, the leaving nucleobase receives a deuteron from the precursor in addition to the ionizing deuteron. Scheme 1 suggests a mechanism, which explains the formation of a charged and c.e. nucleobase from a deuterated RNA precursor. Phosphate-OD is a likely donor of a deuteron because of its acidic properties. Moreover, phosphate and the $3^{\prime}$-neighboring base are likely to interact in the gas phase by hydrogen bonding, e.g., [4]. The C-2' hydrogen is abstracted in the process to create a double-bond between $\mathrm{C}-1^{\prime}$ and $\mathrm{C}-2^{\prime}$. Whether phosphate oxygen interacts directly with C-2' hydrogen (as shown in Scheme 1), or the C-2' hydrogen is transferred to phosphate via successive rearrangements is not known. The signals of charged guanine and cytosine in Figure 1 reveal that 1 Da less than completely exchanged (hereafter 1.t.c.e.) species are also produced. These species are most likely produced by $\mathrm{N}$-glycosidic bond cleavage of a second generation product ion, which already contains a mobilized proton. One major fragmentation pathway for the RNA tetramers, believed to result in such an ion, is $\left[\mathrm{MD}^{+} \rightarrow\right.$ $\mathrm{z}_{3} \rightarrow$ charged nucleobase]; see below.

\section{c-and y-Ions}

$5^{\prime}-\mathrm{P}-\mathrm{O}$ cleavage results in c- and y-type ions, which are commonly observed in RNA fragmentation [10, 11, 15]. Examples of a y-ion and a (y-nucleobase)-ion derived from UCUA is displayed in Figure $1 b$. The UCUA $\mathrm{y}_{3}$-ion is detected as a single peak (a singlet) at $\mathrm{m} / \mathrm{z}$ 892.25, which corresponds to the mass of a c.e. species. All y-ions and all $c_{2}$ - and $c_{3}$-ions of the RNA tetramers analyzed in the current study were observed as c.e. singlets (data not shown). Two things may be concluded from this result. First, no carbon-bound hydro- 
(a)

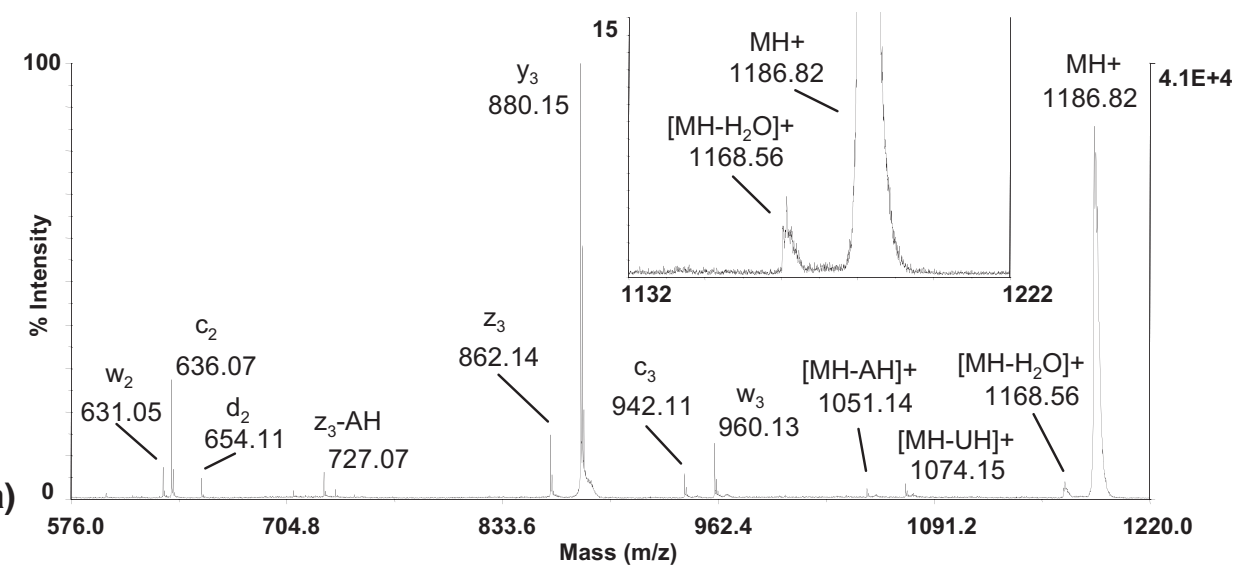

(b)

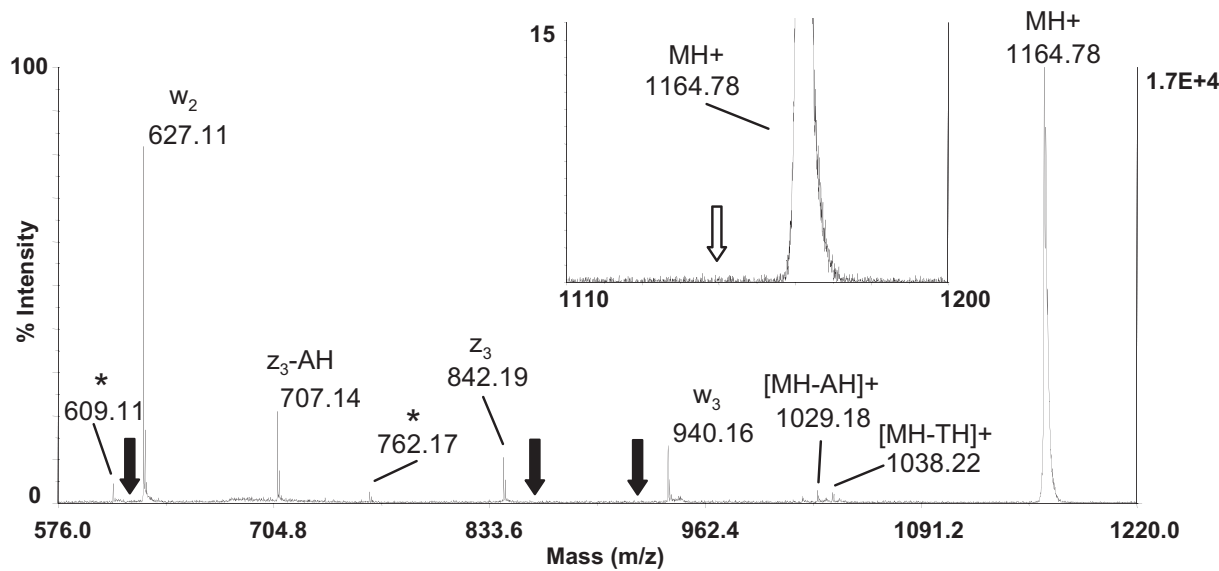

(c)

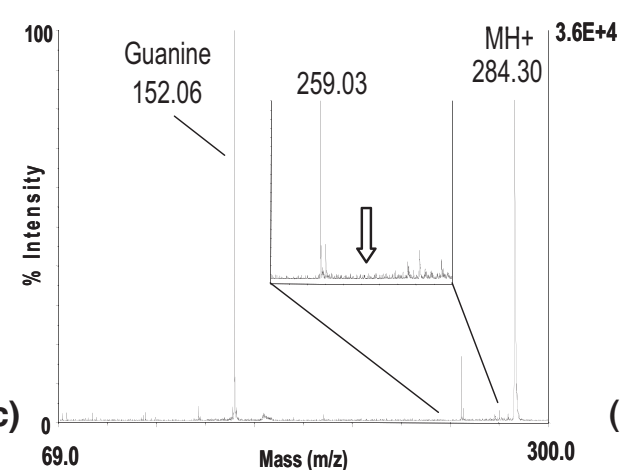

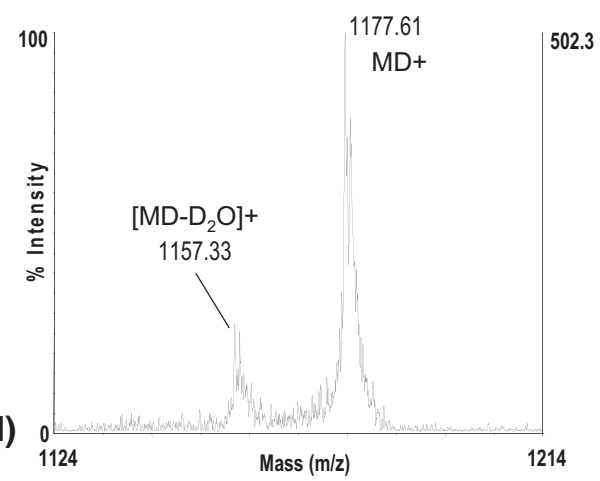

Figure 2. (a) Upper $\mathrm{m} / \mathrm{z}$ region of the tandem mass spectrum of native UAUU oligoribonucleotide. The enlarged spectrum displays the precursor ion $\left(\mathrm{m} / \mathrm{z}\right.$ 1186.82) with associated loss of $\mathrm{H}_{2} \mathrm{O}(\mathrm{m} / \mathrm{z}$ 1168.56). (b) The same $\mathrm{m} / \mathrm{z}$ region in the MS/MS spectrum of native TATT. The enlarged spectrum shows that $\mathrm{H}_{2} \mathrm{O}$ is not lost (open arrow) from the precursor ion $(\mathrm{m} / z$ 1164.78). Filled arrows indicate calculated $m / z$ values of $c-$ and y-ions in this region: $c_{2}(m / z ~ 618), y_{3}\left(m / z 860\right.$ and $c_{3}(m / z ~ 922)$. (asterisk)*: Fragments containing dimerized thymine (cyclobutyl thymidine) [5]. (c) Tandem mass spectrum of native guanine ribonucleoside $(\mathrm{rG})$. Inserted spectrum shows that $\mathrm{H}_{2} \mathrm{O}$ is not lost (open arrow) from the $\mathrm{rG}$ precursor $(\mathrm{m} / \mathrm{z} 284.30) . \mathrm{m} / \mathrm{z} 259.03$ is a thymine ribonucleoside contaminant found in the vial from the manufacturer. (d) Section of the tandem mass spectrum of deuterated UUUU oligoribonucleotide showing the precursor ion $(\mathrm{m} / \mathrm{z} 1177.61)$ and loss of water $(\mathrm{m} / \mathrm{z} 1157.33)$. The ion gating mechanism slightly offsets the $m / z$ values, but in a very consistent manner. Compared with the mass difference attributable to water loss from native UAUU [spectrum (a); $18.26 \mathrm{Da}$ ] the water lost from deuterated UUUU (20.28) is increased $2.02 \mathrm{Da}$. This value is very close to the calculated mass difference between $\mathrm{H}_{2} \mathrm{O}$ and $\mathrm{D}_{2} \mathrm{O}(2.01 \mathrm{Da})$. 
gens are transferred to mobile sites in the cleavage reaction. Secondly, nucleobase loss or other hydrogen mobilizing reactions generally do not precede cleavage of the $5^{\prime}-\mathrm{P}-\mathrm{O}$ bond. Initial loss of a nucleobase would have induced peak splitting of the $\mathrm{c} / \mathrm{y}$-ion fragments due to intramolecular H/DX before 5 '- $\mathrm{P}-\mathrm{O}$ cleavage. The latter is supported by the fact that $\mathrm{c} / \mathrm{y}$-ions associated with nucleobase loss generally were detected as 1 Da 1.t.c.e. singlets, as exemplified by the ( $\mathrm{y}_{3}$-cytosine)ion in Figure 1b $(\mathrm{m} / \mathrm{z}$ 778.24); (c/y-nucleobase)-ions result from a reaction pathway beginning with cleavage of $5^{\prime}-\mathrm{P}-\mathrm{O}$. For the $\left(\mathrm{y}_{3}-\right.$ cytosine)-ion the reaction sequence would be $\left[\mathrm{MD}^{+} \rightarrow \mathrm{y}_{3} \rightarrow\left(\mathrm{y}_{3}\right.\right.$-cytosine $\left.)\right]$.

When inspecting the fragmentation data of the DNA tetramers, it was remarkable that c- and y-ions were completely absent. Figure $2 \mathrm{a}$ and $\mathrm{b}$ illustrate this difference in RNA and DNA fragmentation by comparing native versions of UAUU and TATT. Even when pushing the signal intensity to near the detector-limit, no c- or y-ions could unambiguously be detected for any DNA sample. These results strongly suggest an important role for $2^{\prime}-\mathrm{OH}$ in the cleavage mechanism of $5^{\prime}-\mathrm{P}-\mathrm{O}$, since this group is the only structural difference between RNA and DNA. Another notable difference between the RNA and DNA MS/MS spectra is displayed in the enlarged regions of Figure 2a and b. It is evident that water is lost from the UAUU precursor $(\mathrm{m} / \mathrm{z}$ 1168.56), while this could not be detected for the TATT oligonucleotide (indicated with open arrow). As for the c- and y-ions, the data were consistent in showing neutral loss of water from RNA precursors only, implying that this water is lost from or by the interaction of $2^{\prime}-\mathrm{OH}$. Water loss was not observed in the fragmentation of the 2'-O-methylated UAUC (UmAmUmCm) tetramer either (Figure 3 ), further indicating the involvement of $2^{\prime}-\mathrm{OH}$ in the reaction, and simultaneously ruling out loss of water from the nucleobases.

The RNA-specific loss of water was especially interesting because it may potentially be linked to or result from the mechanism that also produces the RNAspecific c- and y-ions. The origin of water loss was therefore further investigated by tandem mass spectrometric analysis of nucleosides. Fragmentation of guanine and cytosine deoxyribonucleosides did not yield any neutral water loss (data not shown), as expected, from the DNA tetramer results. Surprisingly, water loss was not detected in the dissociation of a guanine ribonucleoside either (Figure 2c, open arrow). This demonstrates that the presence of $2^{\prime}-\mathrm{OH}$ alone is not sufficient to induce the loss of water. Other reactive groups present in RNA, most likely phosphate, are required in the reaction as well. H/DX experiments of oligoribonucleotides yielded further information on the origin of water loss. An all uridine tetramer generated a significant loss of water from the precursor, yielding a signal with clear unit resolution. Figure $2 \mathrm{~d}$ demonstrates that the water lost from deuterated UUUU is a loss of $\sim 20 \mathrm{Da}$, i.e., loss of $\mathrm{D}_{2} \mathrm{O}$. This is an interesting result because a simple dehydration reaction of 2'-OD would be expected to be a loss of HDO, where $\mathrm{C}-1^{\prime}$ or $\mathrm{C}-3^{\prime}$ donates a hydrogen in a 1, 2-elimination reaction.

\section{The 5'-P-O Cleavage Mechanism}

To account for the above described characteristics of RNA fragmentation, we propose a common RNAspecific mechanism to operate in the reactions of water loss as well as $5^{\prime}-\mathrm{P}-\mathrm{O}$ cleavage (Scheme 2). This mechanism is an intramolecular nucleophilic attack on the phosphor atom by the adjacent 2 '-hydroxyl to yield a phosphorane transition state. A similar attack is described in both enzymatic $[16,17]$ and nonenzymatic [18] reactions of RNA hydrolysis in solution. Furthermore, the phosphorane transition state is welldocumented in the mechanism of RNases [18]. In the gas phase, the abstracted 2'-OD deuteron is thought to delocalize between the phosphate oxygens of the phosphorane. Depending on which oxygen acts as leaving group, two products may be detected in the mass spectrometer. If the $\mathrm{P}-\mathrm{OD}$ oxygen departs from the transition state (reaction 1 in Scheme 2), it leaves with the delocalized deuteron leading to neutral loss of $\mathrm{D}_{2} \mathrm{O}$ and formation of an internal $2^{\prime}-3^{\prime}$-cyclic phosphate. If the $5^{\prime}-\mathrm{PO}$ oxygen is the leaving group (reaction 2 ), the result is $5^{\prime}-\mathrm{P}-\mathrm{O}$ cleavage and formation of a "standard" y-type fragment and a c-type fragment with a 3'-terminal 2'-3' cyclic phosphate.

The mechanism of Scheme 2 agrees well with the detection of c.e. c-and y- ions from deuterated precursors, and also accounts for the neutral loss of water observed only for the RNA precursors. Furthermore, this mechanism explains why the water loss from deuterated RNA is a loss of $\mathrm{D}_{2} \mathrm{O}$ and not HDO, which would otherwise be expected from a simple dehydration reaction. In support of this mechanism, the presence of 2'-O-methyl groups in UmAmUmCm greatly impeded the cleavage of $5^{\prime}-\mathrm{P}-\mathrm{O}$ bond. The UAUC MS/MS spectrum in Figure 3 displays significant $C_{2}-$ and $\mathrm{y}_{2}$-ions and a very intense $\mathrm{y}_{3}$-ion, while these ions are barely detectable in the UmAmUmCm spectrum.

The presence of a $2^{\prime}-3^{\prime}$-cyclic phosphate in the $3^{\prime}$ terminus of c-ions would be expected to inhibit loss of this phosphate. On the other hand, if c-ions did not contain a 2'- 3'-cyclic phosphate but instead a $3^{\prime}-$ metaphosphoric-acid ester group, this latter group $\left(\mathrm{HPO}_{3}\right)$ could more easily be lost through cleavage of a single $\mathrm{C}-\mathrm{O}$ bond. We therefore fragmented and analyzed an in-source generated $\mathrm{c}_{2}$-ion from AUCU and compared the fragmentation pattern with that of an enzymatically produced "AU $>\mathrm{p}$ " —an AU dincleotide with a $3^{\prime}$-terminal $2^{\prime}-3^{\prime}$-cyclic phosphate, generated as an incomplete digestion-product of AUCU with RNase A. It is evident from Figure 4a that the AUCU $\mathrm{c}_{2}$-ion does not loose an $80 \mathrm{Da} \mathrm{HPO}_{3}$. This is, as expected, not seen for the $A U>p$ precursor (Figure $4 b$ ) either. The 


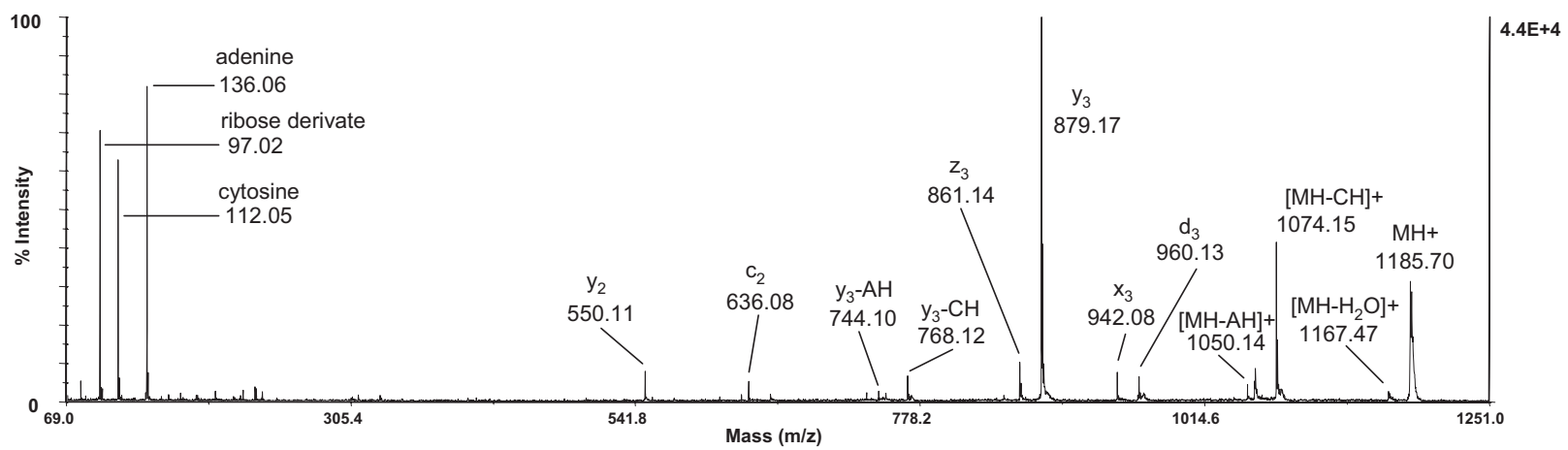

\section{(a)}
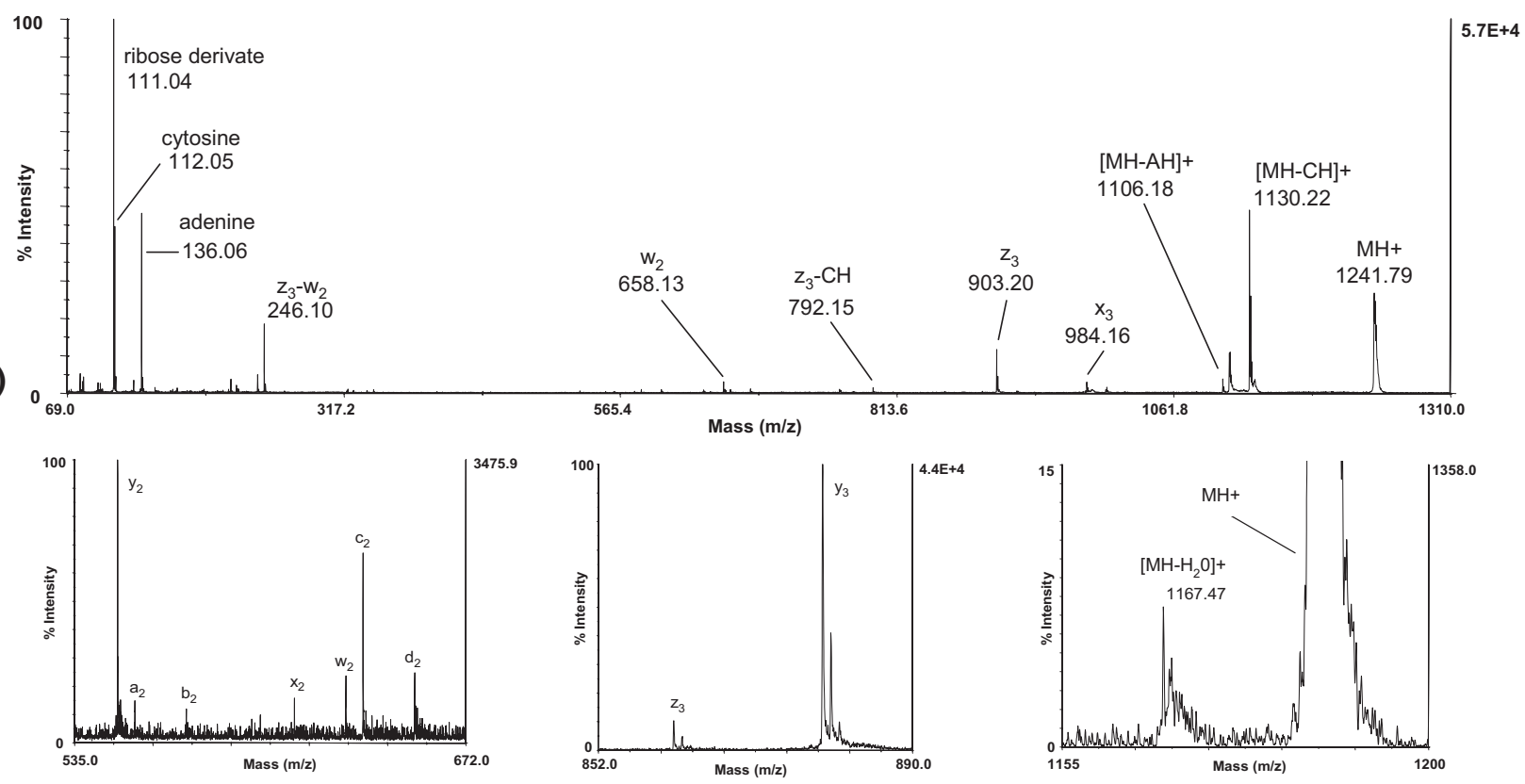

(b)
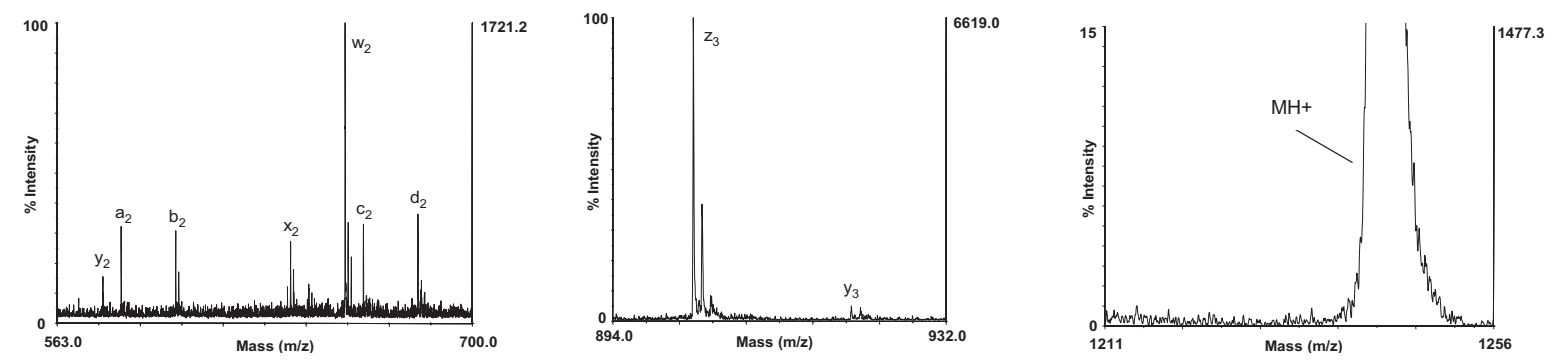

Figure 3. Comparison of the fragmentation of native UAUC and native UmAmUmCm. (a) Full spectra of UAUC (top) and (UAUC)m (bottom). (b) Selected regions of the two spectra enlarged. Left: dinucleotide fragments. Middle: $\mathrm{z}_{3}$ - and $\mathrm{y}_{3}$-ions. Right: precursor ion and the region of neutral water loss.

central $\mathrm{m} / \mathrm{z}$ regions of both spectra in Figure 4 show very little structural information, implying a high stability of the central phosphodiester. Absence of a neutral loss of $\mathrm{HPO}_{3}$ and the generally similar fragmentation pattern of the $c_{2}$-ion and $A U>p$, characterized by a somewhat surprising insusceptibility to fragmentation, represents supporting evidence for the existence of 2 '-3'-terminal cyclic phosphates in c-ions.

The $2^{\prime}-\mathrm{OH}$ group plays an important role in the cleavage mechanism of RNA in solution because the $2^{\prime}$-oxygen can act as an internal nucleophile in the cleavage reaction. Cleavage mechanisms of the $5^{\prime}-\mathrm{P}-\mathrm{O}$ bonds of RNA, which involve intramolecular attack of 2 -oxygen on the neighboring phosphate, takes place in aqueous solution under various circumstances as described above [16-18]. Although the gas-phase conditions differ from aqueous solution, likely $2^{\prime}$-oxygen also acts as nucleophile in the dissociation of the $5^{\prime}-\mathrm{C}-\mathrm{O}$ bond in the mass spectrometer. In this scenario, the nucleophilic attack by 2 -oxygen and formation of the 


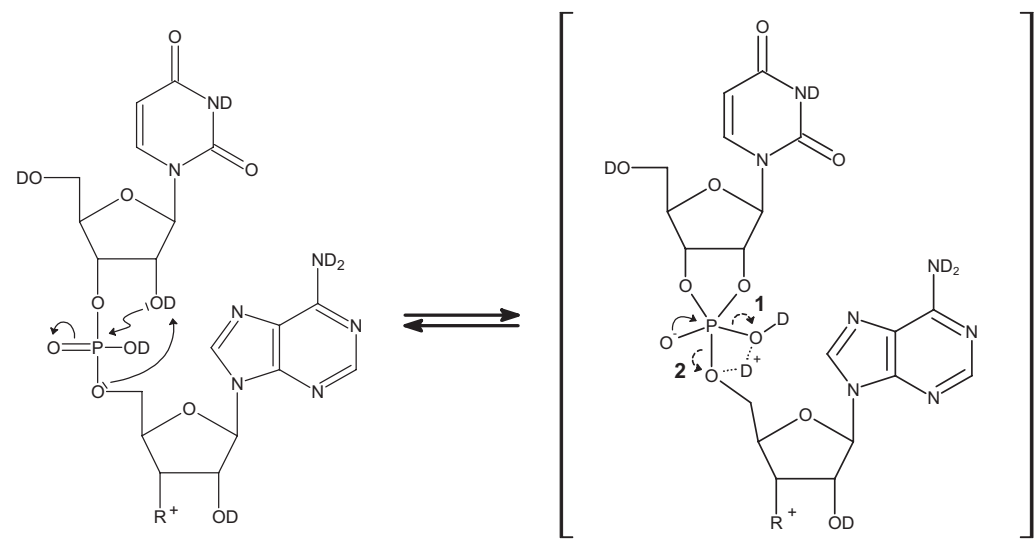

$\mathrm{MD}+$

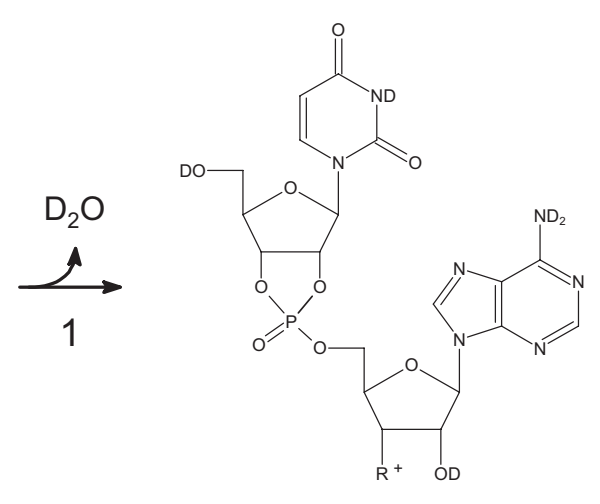

$\left[\mathrm{MD}-\mathrm{D}_{2} \mathrm{O}\right]+$
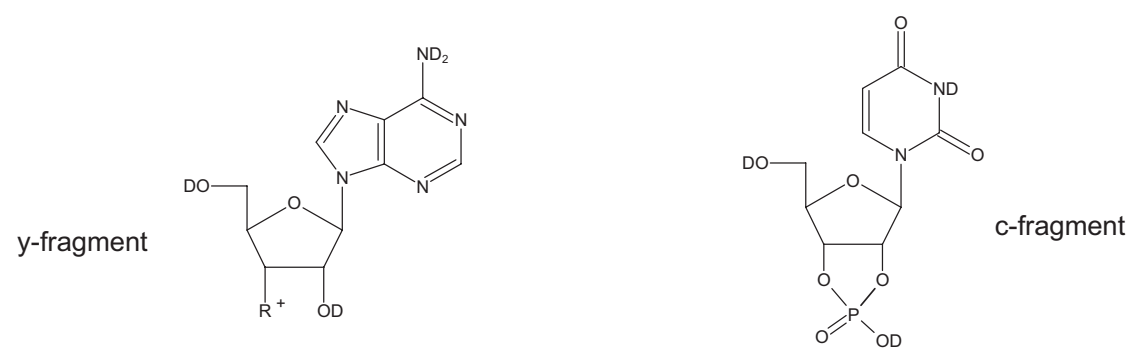

Scheme 2. Proposed fragmentation scheme for c- and y-ion formation from a deuterated RNA precursor. The reaction is a nucleophilic attack by $2^{\prime}$-hydroxyl on the phosphor atom. Although a separation of charged is shown, the abstracted 2'-OD deuteron is thought to be stabilized by delocalization between the phosphate oxygens. The abstracted deuteron travels with the leaving group oxygen resulting in either reversal of the reaction, conversion to a phosphodiester emanating from $\mathrm{C}^{\prime} 2^{\prime}$ (not shown), loss of neutral water (reaction 1) or cleavage of the $5^{\prime}-\mathrm{P}-\mathrm{O}$ bond (reaction 2).

phosphorane structure is induced by the excess energy from the laser irradiation or gas collision. The reaction may be facilitated by the compact structure required for desolvation in the gas phase.

When scrutinizing the literature for information on c- and y-ions generated from positive DNA ions, we have noted that these ions are generally not observed, or their assignment is ambiguous, i.e., with other potentially overlapping peaks. DNA anions, however, do seem to produce $\mathrm{c} / \mathrm{y}$-ions upon fragmentation [3]. It is likely that the location of the negative charge on the phosphodiester backbone affects the stability of the $5^{\prime}-\mathrm{P}-\mathrm{O}$ bond, and that cleavage of this bond in negative DNA or RNA ions can occur by attack of the $\mathrm{PO}^{-}$ oxygen and thus is less dependent on $2^{\prime}-\mathrm{OH}$.

\section{a-Ions}

Although thymidine has the lowest proton affinity of the deoxyribonucleotide bases, our data indicated a not insignificant loss of thymine from DNA precursors, in accordance with the data reported by Gross et al. [5]. The variable thymine loss from DNA precursors to some extend impede an unambiguous interpretation of (a)

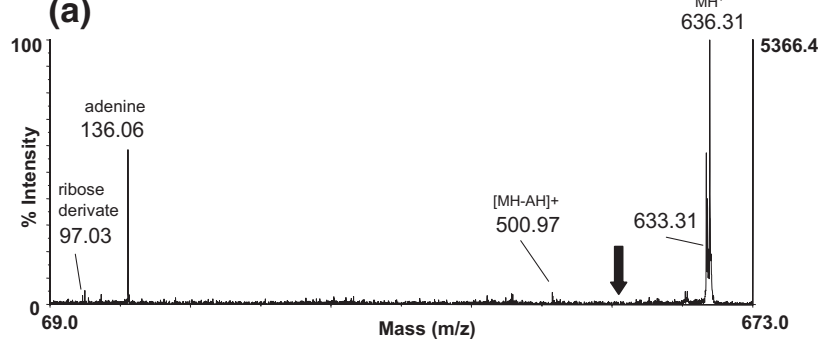

(b)

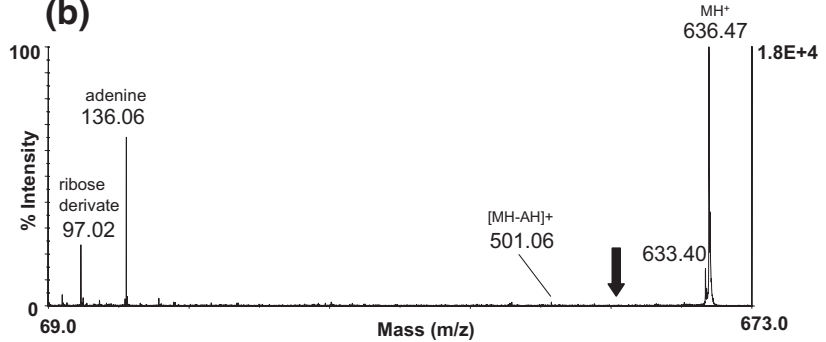

Figure 4. (a) Pseudo $\mathrm{MS}^{3}$ analysis of an in-source generated $\mathrm{c}_{2}$-ion $(\mathrm{m} / \mathrm{z}$ 636.31). (b) Tandem mass spectrum of an AU dinucleotide with a $2^{\prime}-3^{\prime}$-cyclic phosphate in the $3^{\prime}$-terminus. The signal at $\mathrm{m} / \mathrm{z} 633$ is of unknown origin; it could not be effectively excluded by precursor ion selection. Filled arrows indicate the hypothetic $\mathrm{m} / \mathrm{z}$ value for loss of $\mathrm{HPO}_{3}$. 
the DNA H/DX-MS/MS data. For RNA fragmentation, however, the low PA nucleotide uridine was generally found to be much more stable. Only when a uridine was located in the $3^{\prime}$-terminus it was possible to detect a minor loss of uracil (this is in accordance with the lower stability reported for $3^{\prime}$-terminal nucleobases $[4,19,20]$. Loss of uracil nucleobases therefore could be neglected as a possible hydrogen mobilization event before backbone cleavage. This made the RNA H/DX-MS/MS data more easily interpretable and yielded interesting and more clear-cut evidence for the general fragmentation mechanisms of oligonucleotides. Table 1 summarizes the data collected from H/DX-MS/MS analysis of the six analyzed RNA-tetramers; below the table are examples of the peaks and peak-splitting detected. All a-ions are observed as 1 Da 1.t.c.e. singlets suggesting that: (1) one specific mechanism operates in formation of this ion species; (2) no hydrogen-mobilizing fragmentation event, such as neutral nucleobase loss, takes place before this cleavage. The H/DX data alone could, in theory, be explained by formation of $3^{\prime}-5^{\prime}$ cyclic phosphate a-ions with no associated hydrogen mobilization.

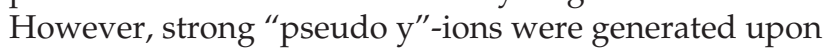
fragmentation of in-source generated $\mathrm{a}_{2}$-ions (a pseudo $\mathrm{MS}^{3}$ ] analysis, data not shown); this would not be expected from $3^{\prime}-5$ '-cyclic phosphate a-ions since simultaneous cleavage of two bonds is required. A third characteristic of the mechanism producing the a-ions can therefore be assumed; a carbon-bound hydrogen is transferred to a mobile site in the a-ion.

Both $5^{\prime}$ phosphate-OD and 2'-COD could be involved in the reaction and donate a deuteron to the neutral w-fragment. 5' Phosphate OD is, however, the most likely interacting group since $\mathrm{a}-$ and $\mathrm{w}$-ions were detected at comparable intensities in the fragmentation of the all 2'-O-methylated UmAmUmCm and the unmodified UAUC (Figure 3). Scheme 3 is the suggested reaction of direct 3'-C $-\mathrm{O}$ cleavage of RNA. The reaction resembles that for DNA following 5'-nucleobase loss suggested by Gross et al. [5]. Our DNA data showed 1 Da 1.t.c.e. a-ions (Table 2), thus supporting this mechanism for DNA also. However, our DNA data does not support the proposal by Gross et al. that nucleobase loss is the initial event in all backbone fragmentation [5, 7]. Loss of a nucleobase would result in mobilization of a hydrogen and intramolecular $\mathrm{H} / \mathrm{D}$-exchange (scrambling) before subsequent fragmentation events. This would immediately be observed in the spectrum as peak splitting. This was generally not observed for higher intensity a-ions, and nucleobase loss before a-ion formation is consequently an infrequent event. Lastly, $\mathrm{a}_{1}$-ions are also observed as 1 Da l.t.c.e. singlets although no $5^{\prime}$ neighboring phosphate is present to donate a deuteron in the reaction. In this specific case, 5 '-OD most likely donates the required deuteron.

\section{(a-B)- and w-Ions}

Our interpretation of the a-, (a-B)-, and w-ion data reveal some general rules that we believe govern $3^{\prime}-$
C - O cleavage of many types of oligonucleotides. Theoretically, the reaction producing the $1 \mathrm{Da}$ l.t.c.e. a-ions will result in a fully deuterated $\mathrm{w}$-ion (Scheme 3 ). Table 1 shows that $\mathrm{w}$-ions from RNA fragmentation also occur as 1 and 2 Da l.t.c.e. species (the same was observed for DNA fragmentation, data not shown), thus demonstrating that two other pathways operate in the formation of w-ions, but without concurrent formation of a-ions. The suggested mechanism is depicted in Scheme 4. Loss of a neutral nucleobase causes the mobilization of one hydrogen. The presence of c.e., $1 \mathrm{Da}$ 1.t.c.e. and 2 Da 1.t.c.e. $\mathrm{w}$-ions as well as (a-B)-ions (Table 1 for RNA, data not shown for DNA) suggests that the nucleobase loss can be followed by two 3'-C-O cleavage reactions. Considering 100\% scrambling, mechanism 1 of Scheme 4 will result in c.e. and 1 Da 1.t.c.e. $\mathrm{w}$-ions in combination with 1 Da 1.t.c.e. and 2 Da 1.t.c.e. (a-B)-ions; mechanism 2 of Scheme 4 will result in $1 \mathrm{Da}$ 1.t.c.e. and $2 \mathrm{Da}$ 1.t.c.e. $\mathrm{w}$-ions in combination with c.e. and 1 Da l.t.c.e. (a-B)-ions. Thus, all levels of exchange on (a-B)- and w-ions are accounted for by Scheme 4 . Lastly, it should be noted that 1- and 2 Da 1.t.c.e. (a-B)-ions were always the strongest peaks in the (a-B)ion signals in both RNA (Table 1) and DNA (not shown) MS/MS spectra. This might indicate that mechanism 1 of Scheme 4 dominates the reaction sequence.

The fact that complementary $\mathrm{w}$ - and (a-B)-ions are typical DNA sequence ions indicates that initial nucleobase loss specifically weakens the $3^{\prime}-\mathrm{C}-\mathrm{O}$ bond of the 3'- adjacent phosphodiester group, producing this characteristic ion-pair immediately after nucleobase loss. An important factor is the driving force towards producing the energetically stable furan ring in an (a-B)-fragment (Scheme 4) as previously suggested [21]. Considering our suggested mechanism for $3^{\prime}-\mathrm{C}-\mathrm{O}$ cleavage, the highly probable hydrogen bonding interactions [4] between phosphate and the 3'-neighboring base in the gas phase (Scheme 5) probably impacts the $3^{\prime}-\mathrm{C}-\mathrm{O}$ cleavage. Hydrogen bonding interactions between phosphate $\mathrm{OH} / \mathrm{D}$ and the $3^{\prime}$-neighboring base would partly prevent the former group from interacting with $3^{\prime}-\mathrm{CO}$ oxygen in cleaving the $3^{\prime}-\mathrm{C}-\mathrm{O}$ bond as required by mechanism 1 in Scheme 4 . The consequence of nucleobase loss is that the phosphate $\mathrm{OH} / \mathrm{D}$ can freely interact with $3^{\prime}-\mathrm{CO}$ and promote fast cleavage into $\mathrm{W}^{-}$and (a-B)-ions. This reaction sequence is particularly pronounced in DNA fragmentation, but our RNA data suggest the same mechanism operates for this species. The H/DX-MS/MS data of both RNA and DNA suggest that $3^{\prime}-\mathrm{C}-\mathrm{O}$ becomes highly unstable and is the preferred site of cleavage upon nucleobase loss. One observation indirectly indicating this is that sequence ions other than $\mathrm{w}$ and $(\mathrm{a}-\mathrm{B})$ were most often detected as singlets (data not shown), i.e., they are products of reactions not preceded by nucleobase loss. Comparing the fragmentation of different base-sequences also indicated the strong correlation between nucleobase loss and 3'- 
Table 1. a-, (a-B)- and w-Ion signals observed in the tandem mass spectra of completely exchanged RNA tetramers. Values in italics are ambiguous signals, with other signals potentially overlapping. Analysis of the native tetramers showed that + (dagger) contain both the $a_{1}$-ion and the isobaric $z_{1}$-ion and $\ddagger$ (double dagger) is predominated by the $z_{3}$-ion. Numbers in parentheses show the deviance in Da from the calculated mass of a completely exchanged fragment ion. In case of peak splitting, the approximate intensity ratios generalized from several spectra of the same precursor are given below. * (single asterisk): low intensity ions. No intensity ratios are given here because of poor ion statistic. n.o.: not observed. ** (double asterisk): interrupted by signals from metastable fragmentation. Examples of peaks and peak splitting are shown below the table (from left; $\mathrm{a}_{2} / \mathrm{UCUA}$, $\mathrm{a}_{3}-\mathrm{B}_{3} / \mathrm{AUCU}, \mathrm{w}_{3} / \mathrm{UCUA}$ and $\mathrm{w}_{2}$ /UGUC).

\begin{tabular}{|c|c|c|c|c|c|c|}
\hline & UAUU & UGUU & UAUC & UCUA & UGUC & AUCU \\
\hline$a_{1}$ & $230(-1)$ & $230(-1)$ & $230(-1) \dagger$ & $230(-1)$ & $230(-1) \dagger$ & $254(-1)$ \\
\hline$a_{2}$ & $563(-1)$ & n.o. & n.o. & $539(-1)$ & n.o. & $563(-1)$ \\
\hline$a_{3}$ & $872(-1)$ & n.o. & $872(-1) \ddagger$ & $848(-1) *$ & n.o. & $872(-1)$ \\
\hline$a_{2}-B_{1}$ & n.o. & n.o. & n.o. & n.o. & n.o. & $425,426 *(-2,-1)$ \\
\hline$a_{2}-B_{2}$ & $425,426,427 *(-2,-1,0)$ & $\begin{array}{c}425,426(-2,-1) \\
50 / 50\end{array}$ & n.o. & n.o. & n.o. & n.o. \\
\hline$a_{3}-B_{1}$ & n.o. & n.o. & n.o. & n.o. & n.o. & $734 *(-2)$ \\
\hline$a_{3}-B_{2}$ & assigned to $z_{3}-B_{2}$ & assigned to $z_{3}-B_{2}$ & n.o. & n.o. & n.o. & assigned to $a_{3}-B_{3}$ \\
\hline$a_{3}-B_{3}$ & n.o. & n.o. & n.o. & n.o. & n.o. & $\begin{array}{c}758,759(-2,-1) \\
60 / 40\end{array}$ \\
\hline$w_{1}$ & n.o. & n.o. & n.o. & $354,355 *(-2,-1)$ & n.o. & n.o. \\
\hline$w_{2}$ & $638,639,640(-2,-1,0)$ & $638,639,640(-2,-1,0)$ & $639,640 *(-1,0)$ & $662,663,664(-2,-1,0)$ & $638,639,640(-2,-1,0)$ & n.o. \\
\hline & $30 / 40 / 30$ & $30 / 40 / 30$ & & $10 / 50 / 40$ & $20 / 40 / 40$ & \\
\hline$w_{3}$ & $973(0)$ & $990 *(0)$ & n.o.** & $973(0)$ & n.o. & $947,948 *(-2,-1)$ \\
\hline
\end{tabular}
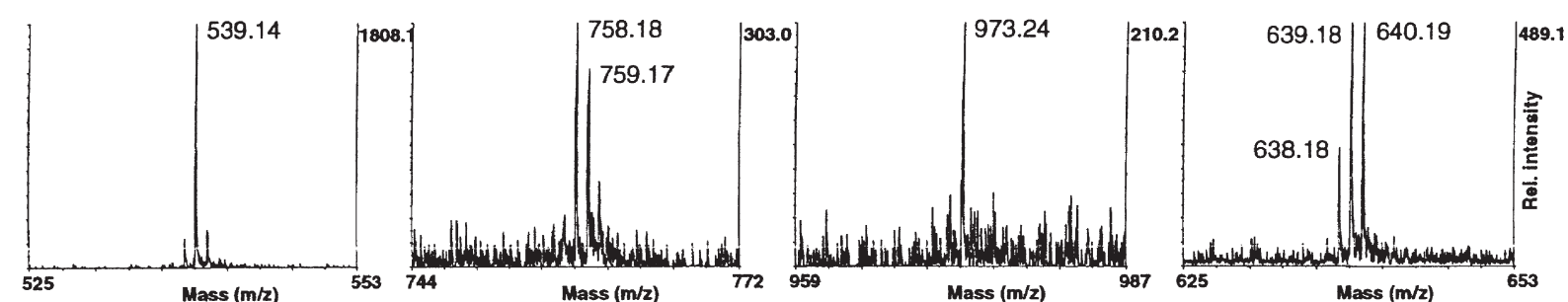


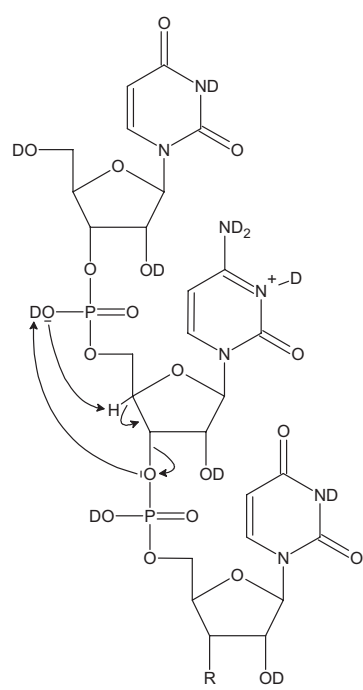

$\mathrm{MD}+$

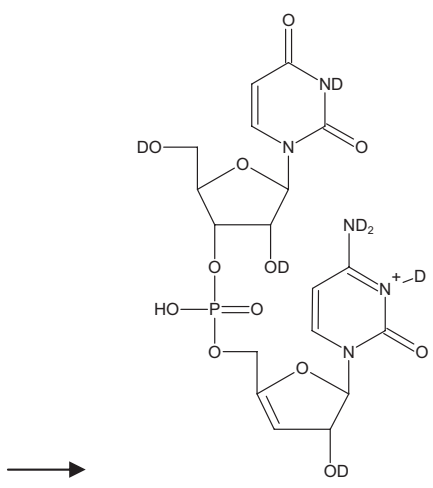

a-fragment

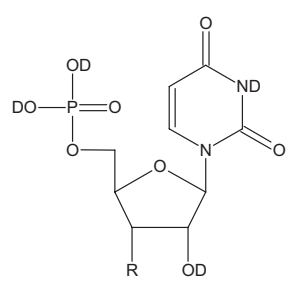

w-fragment
Scheme 3. Proposed fragmentation mechanism of direct $3^{\prime}-$ $\mathrm{C}-\mathrm{O}$ cleavage.

C-O cleavage. For example, our RNA data showed strong $\mathrm{w}$ - or (a-B)-ions when the especially labile [10] guanine nucleobase is the $5^{\prime}$-neighbor. When other bases are the immediate 5'-neighbor, (a-B)- and $\mathrm{w}$ ions are less intense, while c- and y-ions occur at higher relative intensities (data not shown). The latter observation also suggests that the RNA-typical fragmentation pattern of strong $c$ - and $y$-ions and weaker a-, (a-B)-, and w-ions results from generally more stable nucleobases in the RNA oligonucleotide [22]. However, we propose an additional stabilizing factor specific for RNA in the $3^{\prime}-\mathrm{C}-\mathrm{O}$ cleavage mechanism. The "internal solvation" of RNA in the gas phase by interactions between $2^{\prime}-\mathrm{OH}$, and phosphate stabilizes the desorbed ion [4]. Upon loss of a nucleobase in the RNA oligonucleotide, 2'-OH provides an additional interacting group [4], which stabilizes phosphate via proton sharing (Scheme 5). Phosphate-OH is therefore not immediately available in the $3^{\prime}-\mathrm{C}-\mathrm{O}$ cleav- age reaction (mechanism 1 in Scheme 4), and loss of a nucleobase from RNA results in a less dramatic decrease in stability of the neighboring $3^{\prime}-\mathrm{C}-\mathrm{O}$ bond. Comparable data from the similar RNA and DNA tetramers (TATT/UAUU, TATC/UAUC, and TCTA/UCUA) support this suggested additional stabilizing feature of the RNA. Almost equal $\left(\mathrm{M}-\mathrm{B}_{2}\right)$-ion abundances were observed between RNA and DNA, whereas subsequent $3^{\prime}-\mathrm{C}-\mathrm{O}$ cleavage into $\mathrm{w}_{2}$ was much less pronounced for RNA (data not shown). No other significant second generation fragments of the first generation $\left(\mathrm{M}-\mathrm{B}_{2}\right)$-ions were produced; $\mathrm{w}_{2}$ is thus the prime dissociation product of this ion. The data indicate a lower rate of $\left(\mathrm{M}-\mathrm{B}_{2}\right)$ to $\mathrm{w}_{2}$ conversion for the RNA species. The equal RNA/DNA intensities of $\left(\mathrm{M}-\mathrm{B}_{2}\right)$, despite DNA having significantly more labile $\mathrm{N}$-glycosidic bonds, probably result from a longer life time of the RNA $\left(M-B_{2}\right)$ ions (Scheme 5), which to some extend "evens out" the differences in N-glycosidic bond stability.

Our presented data provide evidence for different stabilizing features in the structures of RNA and DNA during their decay in mass spectrometry. However, our observation of scrambling between different fragmentation events suggests that these ions are, at the same time, highly dynamic. For this reason, the schemes shown should be viewed as possible conformations that are favored-but not absolute-in a very dynamic and flexible structure. Lastly, it should be noted that the structural flexibility and rate of intramolecular H/DX may be significantly lower in the fragmentation of longer chains of DNA/RNA.

\section{The Direct 3'-C-O Cleavage Mechanism}

Strong intensity a-ions of both RNA and DNA were detected as singlet ions (Tables 1 and 2) indicating that nucleobase loss does not occur before generation of these ions. This is substantiated by a general absence of (w-B)-ions in the MS/MS spectra (data not shown). Wang et al. [23] previously suggested, based on the observation of abundant a-ions from fragmentation of different modified oligodeoxyribonucleotides, that backbone cleavage might not always require nucleobase loss. Our data provides evidence to substantiate

Table 2. a-Ions derived from completely exchanged DNA tetramers. Symbols as in Table 1 To the left is shown a singlet $\mathrm{a}_{2}$-ion peak from TCTA.

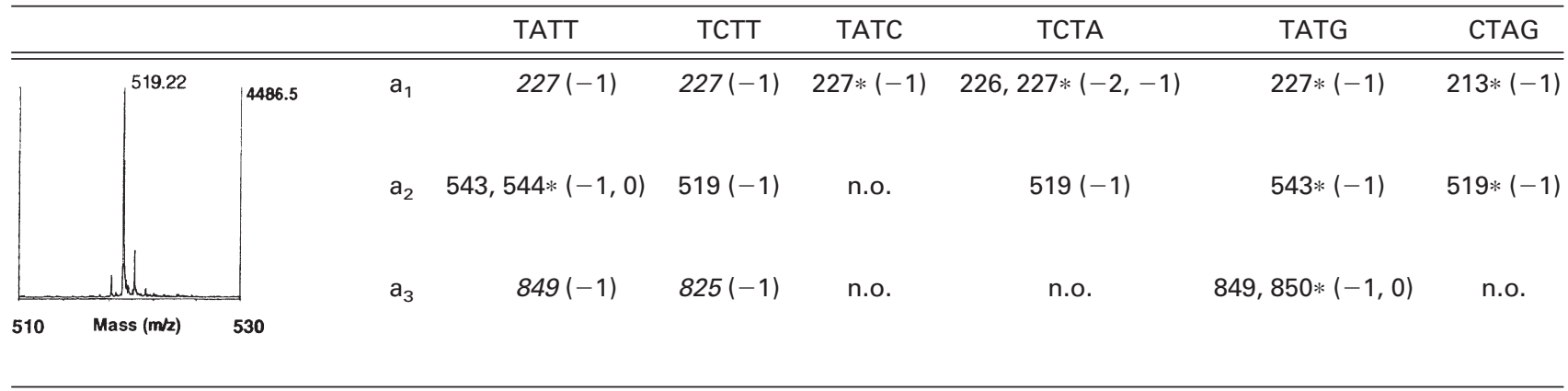




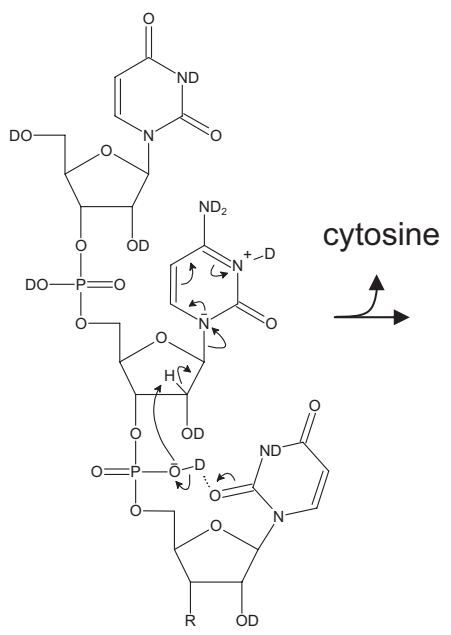

$\mathrm{MD}+$

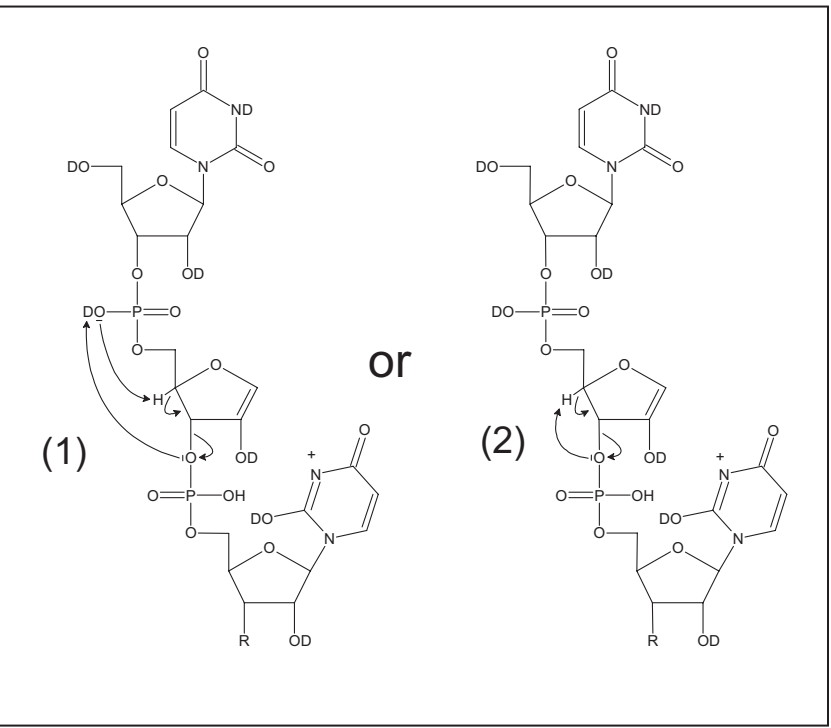

$[\mathrm{MD}-\mathrm{CD}]+$

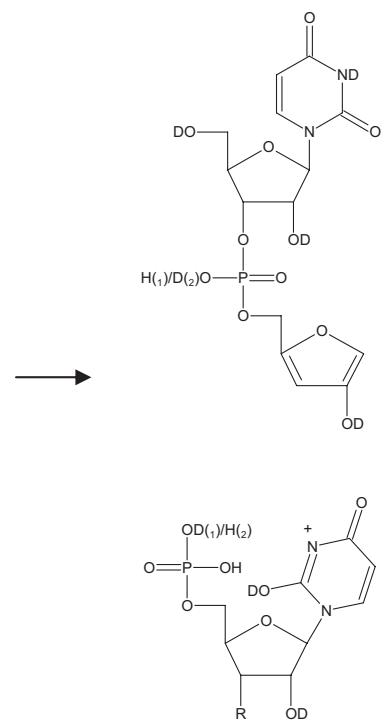

(a-B)- and wfragments

Scheme 4. Proposed mechanism of nucleobase loss-preceded $3^{\prime}-\mathrm{C}-\mathrm{O}$ cleavage. The possibility for intramolecular H/DX upon nucleobase loss is not shown.

this suggestion. In the same paper, Wang et al. [23] proposed a $3^{\prime}-\mathrm{C}-\mathrm{O}$ cleavage mechanism involving the abstraction of $4^{\prime}-\mathrm{C}$ hydrogen by the $3^{\prime}$-phosphodiester. Our data clearly show that a-ions receive one carbon- bound hydrogen upon $3^{\prime}-\mathrm{C}-\mathrm{O}$ cleavage and nonnucleobase loss preceded $\mathrm{w}$-ions are primarily c.e. species. Thus, the carbon-bound hydrogen is instead transferred in the $5^{\prime}$-direction, most likely abstracted by

RNA<smiles></smiles>
-adenine
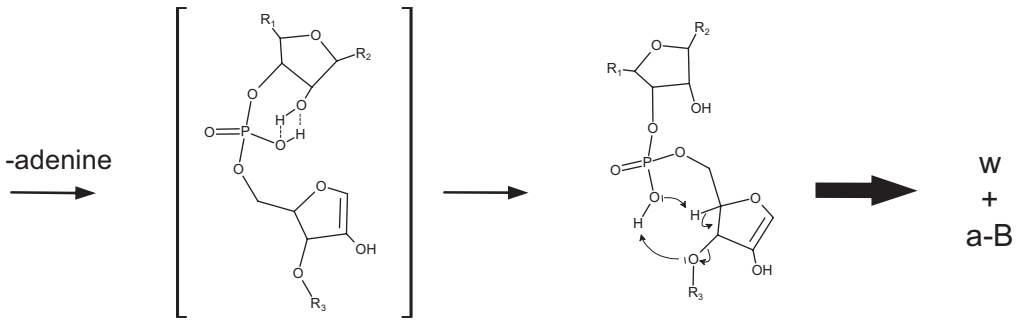

"released" phosphate $\mathrm{H}$

DNA
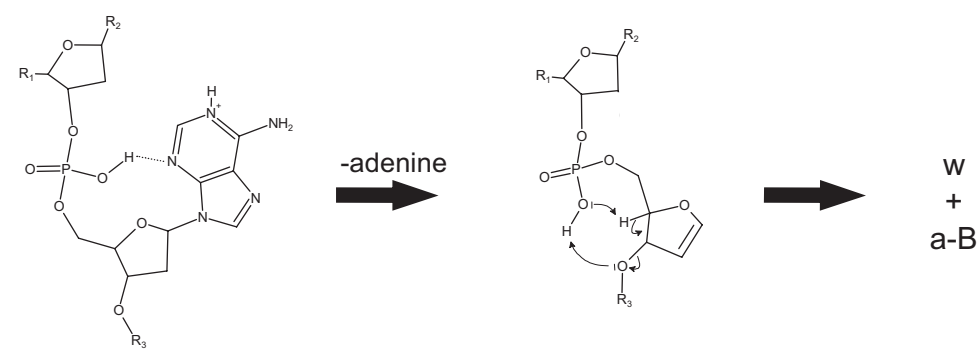

Scheme 5. RNA and DNA showing loss of an adenine followed by $3^{\prime}-\mathrm{C}-\mathrm{O}$ bond cleavage. Structures are optimized for correct bond angles (using 3D structure optimization in the ACD/ ChemSketch software). The scheme illustrates how phosphate-base hydrogen bonding in the gas phase represses a subsequent 3 '- $\mathrm{C}-\mathrm{O}$ bond cleavage. The N-glycosidic bonds in DNA are less stable than in RNA leading to a more extensive production of (M-nucleobase)-ions from DNA precursors. The RNA (M-nucleobase)-ions are transiently stabilized by proton sharing between phosphate and $2^{\prime}$-OH. Absence hereof in DNA leads to 3'-C-O cleavage in rapid succession to nucleobase loss. Large and small arrows indicate favored and less favored reactions/rearrangements. 
an oxygen in the $5^{\prime}$ neighboring phosphodiester as suggested in a longer DNA fragmentation pathway by Gross et al. [5] and as proposed here for RNA (Scheme 3). Interestingly, Wang et al. [23] also found that placement of methylphosphonates in the central region of a mixed sequence phosphothioate-methylphosphonate oligodeoxyribonucleotide inhibited a-ion formation in this region. This is consistent with the proposed mechanism (Gross et al. [5] and Scheme 3), because no reaction-initiating $\mathrm{P}-\mathrm{OH}$ hydrogen exists in the methylphosphonate. Minor signals from the complementary $\mathrm{w}$-ions were detected in phosphothioate-methylphosphonate oligodeoxyribonucleotides [23]; these are most likely generated in a $\left[\mathrm{MH}^{+} \rightarrow(\mathrm{MH}-\mathrm{B})^{+} \rightarrow \mathrm{w}\right]$ sequence where the last step is the proposed 1,2elimination reaction allowed upon nucleobase loss (Scheme 4, mechanism 2).

\section{Nucleobase Loss Drives Subsequent Site-Specific $3^{\prime}-\mathrm{C}-\mathrm{O}$ cleavage}

The $(a-B) / w$ ion-pairs are abundant species in mass spectrometric fragmentation of DNA regardless of ionization method and ion polarity. Various mechanisms have been proposed for the loss of a nucleobase and subsequent cleavage of the $3^{\prime}-\mathrm{C}-\mathrm{O}$ bond [3]. For negative DNA-ions, only the mechanism proposed by $\mathrm{Z}$. Wang et al. [9] rationalizes why the $3^{\prime}-\mathrm{C}-\mathrm{O}$ bond is site-specifically cleaved on the deoxyribose from which the nucleobase is lost. This mechanism involves protonation of the nucleobase by the adjacent 5 '-phosphate$\mathrm{OH}$, followed by loss of this nucleobase and formation of a zwitterionic intermediate. In this zwitterionic intermediate, negatively charged phosphate oxygen promotes abstraction of C-4' hydrogen on the $3^{\prime}$-neighboring deoxyribose leading to rapid and site specific cleavage of this $3^{\prime}-\mathrm{C}-\mathrm{O}$ bond. Further studies to substantiate this fragmentation mechanism of negative DNA-ions were later presented in [6, 7, 24]. In a mechanism of neutral nucleobase loss earlier proposed for positive DNA-ions [5], which is in agreement with the data obtained here, the nucleobase leaves with the excess proton and does not abstract the nearby phosphate-OH hydrogen (Scheme 4). Early works on oligonucleotide fragmentation have shown that protonation destabilizes the nucleobase [22, 25-28], which substantiates the mechanism proposed in Scheme 4 and strongly indicates that the nucleobase carrying the excess positive charge is much more prone to cleavage than other nucleobases in the oligonucleotide. The excess proton on nucleobases of positive oligonucleotide ions allows cleavage of the N-glycosidic bond without separation of charge and formation of a likely energetically unfavorable zwitterion. Hence, a chargepromoted reaction of nucleobase loss (Scheme 4) would be favored in positive ions over the charge-remote zwitterion reaction. Albeit disfavored, the latter reaction is possible in positive ions. This may explain why
Chou et al. [13] still observed (a-B)- and w-ions for positive DNA-ions with charge tagged $5^{\prime}$ - or $3^{\prime}$-termini.

Since nucleobase loss from positive oligonucleotide ions does not involve a zwitterion, this reaction sequence alone does not explain the favorable generation of $(\mathrm{a}-\mathrm{B}) / \mathrm{w}$ upon $\mathrm{N}$-glycosidic bond cleavage in the positive ion mode. We believe that for positive oligonucleotide ions, two factors make the $3^{\prime}$-adjacent $3^{\prime}$ $\mathrm{C}-\mathrm{O}$ bond particularly weak as a result of nucleobase loss. One is the favorable generation of a furan from the (a-B)-ion suggested by Nordhoff et al. [21]. The other is the release of the hydrogen-bonded phosphate-OH (Scheme 5) upon nucleobase loss, making this hydrogen available and highly reactive in a following $3^{\prime}-\mathrm{C}-\mathrm{O}$ cleavage mechanism. It is interesting that Wang et al. [23] reported abundant a-ion series and little signal due to (a-B)-ions when fragmenting all-phosphothioatemodified oligodeoxyriboncleotides. Our proposed relationship between nucleobase loss and $3^{\prime}-\mathrm{C}-\mathrm{O}$ cleavage is in agreement with these data: $\mathrm{S}-\mathrm{H}$ bonds are less polar than $\mathrm{O}-\mathrm{H}$ bonds, and hydrogen bonding with sulfhydryl groups is consequently considerably weaker than with hydroxyl groups. Phosphothioates are therefore less associated with the neighboring nucleobase through hydrogen bonding, making the SH-hydrogen more accessible in a $3^{\prime}-\mathrm{C}-\mathrm{O}$ cleavage reaction and, consequently, $3^{\prime}-\mathrm{C}-\mathrm{O}$ cleavage less dependent on prior nucleobase loss.

Although the nucleobase loss-controlled $3^{\prime}-\mathrm{C}-\mathrm{O}$ cleavage mechanism appears to operate in both RNAand DNA-fragmentation, the current data imply a slower reaction rate of the former in the conversion $[(\mathrm{MH}-\mathrm{B})+\rightarrow(\mathrm{a}-\mathrm{B}) / \mathrm{w}]$. This behavior may be a result of an alternative, stabilizing interaction between phosphate-OH and 2'-OH (Scheme 5). Kirpekar and Krogh [10] observed multiple nucleobase losses without backbone cleavage, when fragmenting RNA oligonucleotides by CID using a MALDI-QqTOF instrument; such ions are generally not observed for oligodeoxyribonucleotides. It was therefore suggested that a role of 2 '-OH should be taken into consideration in the mechanisms of $(\mathrm{a}-\mathrm{B}) / \mathrm{w}$-ion formation. We did not observe ions of multiple nucleobase losses in the current study, possibly because of a less extensive CID fragmentation in the MALDI TOF-TOF instrument. Their formation in the MALDI-QqTOF instrument, however, could well be explained by the suggested additional stabilization of RNA in the gas phase, offered by hydrogen sharing interactions between $2^{\prime}-\mathrm{OH}$ and the $3^{\prime}$-neighboring phosphate previously suggested by Phillips and McCloskey [4].

\section{$d$ - and z-Ions}

Table 3 lists the observed d- and z-ions in the MS/MS spectra of the six deuterated RNA tetramers. In general, z-ions were observed much more frequently and at much higher intensities than their complementary d-ion species (also considering the location of charge during 
Table 3. $\mathrm{d}$ - and z-Ions observed in the tandem mass spectra of completely exchanged DNA tetramers. Symbols as in Table $1+$ (dagger): contains both the z-ion and the isobaric a-ion; $\ddagger$ (double dagger): dominated by the $\mathrm{z}_{3}$-ion.

\begin{tabular}{|c|c|c|c|c|c|c|}
\hline & UAUU & UGUU & UAUC & UCUA & UGUC & AUCU \\
\hline $\mathrm{z}_{1}$ & $230(-1)$ & $230(-1)$ & $230(-1) * \dagger$ & $254(-1)$ & $230(-1) *$ & $230(-1) *$ \\
\hline$z_{2}$ & $539(-1)$ & $539(-1)$ & $539 *(-1)$ & $563 *(-1)$ & n.o. & $539(-1)$ \\
\hline \multirow[t]{2}{*}{$z_{3}$} & $872(-1)$ & n.o. & $872(-1) \ddagger$ & $872(-1)$ & n.o. & n.o. \\
\hline & UAUU & UGUU & UAUC & UCUA & UGUC & $A \cup C U$ \\
\hline $\begin{array}{l}d_{1} \\
d_{2} \\
d_{3}\end{array}$ & $\begin{array}{c}\text { n.o. } \\
664(0) \\
\text { assigned to } w_{3}\end{array}$ & $\begin{array}{c}\text { n.o. } \\
\text { n.o. } \\
\text { assigned to } w_{3}\end{array}$ & $\begin{array}{l}\text { n.o. } \\
663,664 *(-1,0) \\
\text { n.o. }\end{array}$ & $\begin{array}{l}\text { n.o. } \\
\text { n.o. } \\
\text { n.o. }\end{array}$ & $\begin{array}{l}\text { n.o. } \\
\text { n.o. } \\
\text { n.o. }\end{array}$ & $\begin{array}{c}355(0) * \\
662,663 *(-2,-1) \\
\text { n.o. }\end{array}$ \\
\hline
\end{tabular}

fragmentation). A possible explanation for this difference is that protonation of a base to some extend destabilizes the $5^{\prime}$-neighboring $5^{\prime}-\mathrm{C}-\mathrm{O}$ bond and thereby favors generation of z-ions over $\mathrm{d}$-ions. In agreement with this, cleavage of $5^{\prime}-\mathrm{C}-\mathrm{O}$ bonds located $5^{\prime}$ to the high PA bases adenine or cytosine were found to generate the strongest z-ion signals. For example, UAUC and UCUA generated strong $\mathrm{z}_{3}$-ion signals but almost undetectable $z_{2}$-ions, while AUCU generated a high intensity $\mathrm{z}_{2}$-ion peak but no $\mathrm{z}_{3}$-ions (Table 3 ). Protonated guanine in UGUU is also believed to promote $5^{\prime}-\mathrm{C}-\mathrm{O}$ cleavage. The $\mathrm{z}_{3}$-ion is not detected for this species due to rapid loss of guanine and generation of $\left(z_{3}-B_{2}\right)$, (Figure 1a $m / z \sim 735$ ). $z_{3}-$ and $\left(z_{3}-B\right)$-Ions from UGUC were below the limit of detection.

z-Ions derived from fully deuterated RNA precursors appear as singlet peaks at 1 Da l.t.c.e. Since the signal is not split, nucleobases are not lost before generation of this ion species. The degree of deuteration indicates a $5^{\prime}$-directed transfer of a deuteron and mobilization of a carbon-bound hydrogen. A generally very similar $5^{\prime}-\mathrm{C}-\mathrm{O}$ cleavage pattern of RNA and DNA (e.g., $z_{3}$ in Figure $2 a$ and b), and of UmAmUmCm and UAUC (Figure 3), is in accordance with no important role for the 2 '-substituent in this cleavage reaction. The observed characteristics of $\mathrm{z}$ and d-ions are accounted for in our suggested fragmentation mechanism in Scheme 6. In this chargecontrolled reaction, the deuteron transferred across the site of cleavage is derived from a protonated, 3'-neighboring nucleobase (here cytosine). The involvement of the ionizing deuteron explains the apparent destabilizing influence of a high PA nucleobase on the $5^{\prime}$ adjacent $5^{\prime}-\mathrm{C}-\mathrm{O}$ bond.

Table 4 shows that the general $5^{\prime}-\mathrm{C}-\mathrm{O}$ cleavage pattern of DNA has many of the same characteristics as the RNA tetramers. The only signals detected at $\mathrm{m} / \mathrm{z}$ values corresponding to $\mathrm{d}$-ions are the nominal $\mathrm{d}_{3}$-ions from TATT and TCTT, expected to contain at least a significant amount of $\mathrm{w}_{3}$ and a weak $\mathrm{d}_{2}$-ion signal, which may well be an internal fragment judged from the intensive peak-splitting. The scarce, perhaps absent, d-ions are in contrast to z-ions, which appear to an appreciable extent, and for some precursors, such as $\mathrm{z}_{3}$-ions from the TATT, TATC, and TATG tetramers, generate intense ion signals. There appears to be a higher tendency for $5^{\prime}-\mathrm{C}-\mathrm{O}$ cleavage when located $5^{\prime}$ to a high PA nucleobase, especially adenine. We observed a strong $\left(\mathrm{z}_{3}-\mathrm{B}_{2}\right)$-ion signal in the TCTT MS/MS spectrum (data not shown) indicating a significant generation of $z_{3}$ despite the low intensity of this ion (Table 4). Although some z-ions occur as 2 Da 1.t.c.e., high intensity z-ions signals are detected at $\mathrm{m} / \mathrm{z}$ values corresponding to 1 Da l.t.c.e., i.e., similar to that observed for RNA. Hence, we propose a $5^{\prime}-\mathrm{C}-\mathrm{O}$ fragmentation mechanism for DNA as suggested here for RNA (Scheme 6).

As supporting evidence for the charge-controlled mechanism presented in Scheme 6, Chou et al. [13] did not observe any $5^{\prime}-\mathrm{C}-\mathrm{O}$ cleavage fragments in fragmentation of $3^{\prime}$ - or 5'-charge-tagged oligodeoxyribonucleotides. This is in contrast to the fragmentation pattern observed in the current study for untagged DNA tetramers, where $\mathrm{z}$ - and $\mathrm{z}$-derived ions were frequently observed as intense peaks. The suggested charge-controlled mechanism would not be possible for oligodeoxyribonucleotides with charge tagged in the $5^{\prime}$ or 3'-termini, so absence of z-ions would indeed be expected. Similar MALDI matrices and ion sources were used by Chou et al. as in the current study. $5^{\prime}-\mathrm{C}-\mathrm{O}$ cleavage of DNA has previously been suggested to be initiated by the protonated $3^{\prime}$-adjacent
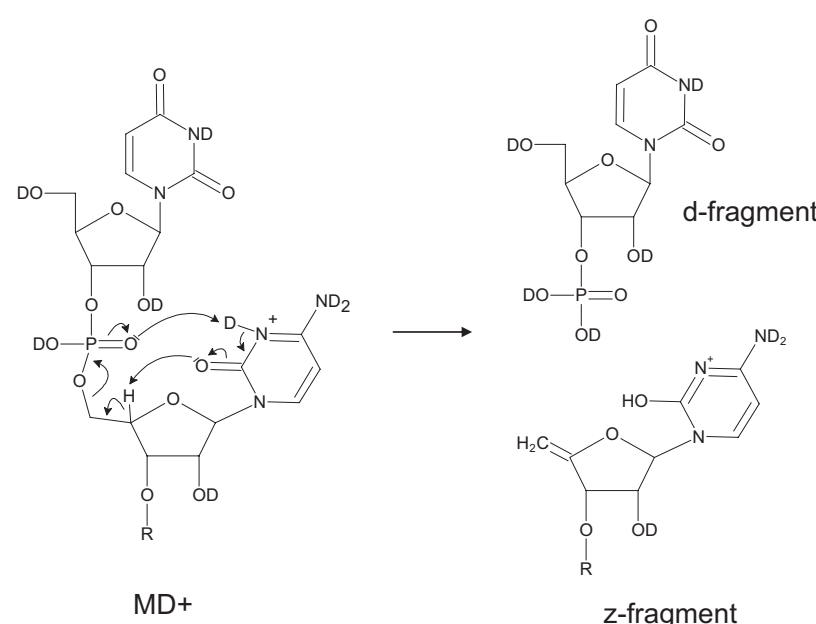

z-fragment

Scheme 6. Proposed fragmentation scheme of $5^{\prime}-\mathrm{C}-\mathrm{O}$ cleavage. 
Table 4. d- and z-Ions observed in the tandem mass spectra of completely exchanged RNA tetramers. Symbols as in Table 1

\begin{tabular}{|c|c|c|c|c|c|c|}
\hline & TATT & TCTT & TATC & TCTA & TATG & CTAG \\
\hline $\mathrm{z}_{1}$ & $227(-1)$ & $227(-1)$ & n.o. & $236,237 *(-2,-1)$ & n.o. & n.o. \\
\hline$z_{2}$ & $532,533 *(-2,-1)$ & $532,533 *(-2,-1)$ & n.o. & $543 *(-1)$ & n.o. & $570 *(-1)$ \\
\hline \multirow[t]{2}{*}{$z_{3}$} & $849(-1)$ & $825 *(-1)$ & $835(-1)$ & $835 *(-1)$ & $876(-1)$ & n.o. \\
\hline & TATT & TCTT & TATC & TCTA & TATG & CTAG \\
\hline $\mathrm{d}_{1}$ & n.o. & n.o. & n.o. & n.o. & n.o. & n.o. \\
\hline $\mathrm{d}_{2}$ & n.o. & n.o. & n.o. & $618,619,620 *(-2,-1,0)$ & n.o. & n.o. \\
\hline$d_{3}$ & assigned to w3 & assigned to w3 & n.o. & n.o. & n.o. & n.o. \\
\hline
\end{tabular}

nucleobase, forming a z-ion with the $5^{\prime}$-terminal carbon atom ring closed to the nucleobase [5]. Our data suggest the involvement of the adjacent, protonated nucleobase, but we find that our frequent detection of strong $\left(z_{3}-B_{2}\right)$-ion signals (e.g., Figure $\left.2 b, m / z 707.14\right)$ does not correlate well with $5^{\prime}$-end ring closure. This would require an unlikely simultaneous cleavage of two bonds in the $\left[z_{3} \rightarrow\left(z_{3}-B_{2}\right)\right]$ reaction.

A reviewer pointed out that loss of the $5^{\prime}$-end nucleobase from z-ions in a reaction as depicted in Scheme 4 would, together with a simple double-bond rearrangement, yield an energetically stable furan ring. It is interesting that our proposed a-B reaction channel (Scheme 4) is a sequence of $\mathrm{N}$-glycosidic and $\mathrm{C}-\mathrm{O}$ bond cleavages occurring in the reverse order as this possible z-B reaction channel. Although speculative, possibly the decay of DNA is determined by nucleobase loss. If initiated by $\mathrm{N}$-glycosidic bond cleavage, $3^{\prime}-\mathrm{C}-\mathrm{O}$ cleavage follows leading to $\mathrm{a}-\mathrm{B} / \mathrm{w}$ ions. If the initial event is backbone cleavage, this is likely to take place at the $5^{\prime}-\mathrm{P}-\mathrm{O}$ bond leading to $\mathrm{z}$ and subsequently $\mathrm{z}-\mathrm{B}$. For RNA, the $5^{\prime}-\mathrm{P}-\mathrm{O}$ cleavage is an additional reaction channel, making the fragmentation pattern of this species more complex.

The fragmentation mechanism proposed here does not readily explain the generation of $\mathrm{d}$ - and z-ions from negatively charged precursors. In this case, it may be that the base protonation required for a chargecontrolled $5^{\prime}-\mathrm{C}-\mathrm{O}$ cleavage of negative ions takes place via donation of a hydrogen from a remote phosphate. It is also possible, as suggested here for cleavage of the $5^{\prime}-\mathrm{P}-\mathrm{O}$ bonds, that a different, simpler reaction mechanism takes place, induced by the nearby negative charge. This could be a simple elimination reaction initiated by abstraction of $\mathrm{C}^{-} \mathrm{4}^{\prime}$ hydrogen by the nearby $\mathrm{PO}^{-}$oxygen.

\section{Conclusions}

Several important findings were made in the current study, which shed light on the mechanisms underlying gas-phase fragmentation of RNA and DNA in positive mode MALDI mass spectrometry. It was previously proposed that all backbone fragmentation of DNA is dependent on initial nucleobase loss. We obtained evidence, which imposes some modifications to this proposal. Only formation of the classic $(\mathrm{a}-\mathrm{B}) / \mathrm{w}$-ion pair appears to depend strongly on prior nucleobase loss. Our data suggest that loss of a nucleobase in an oligodeoxyribonucleotide renders the 5 '-neighboring $3^{\prime}-\mathrm{C}-\mathrm{O}$ bond extremely unstable, leading to a sitespecific cleavage of this bond and no other in the phosphodiester backbone. a- and z-Ions, for example, which often appear in the DNA MS/MS spectrum, are generally not preceded by nucleobase loss.

It was interesting to find that backbone fragmentation of RNA is dependent on prior nucleobase loss similar to DNA, i.e., only in the nucleobase loss $\rightarrow$ $3^{\prime}-\mathrm{C}-\mathrm{O}$ cleavage reaction. Generally, the fragmentation mechanisms undergone by RNA appear to be the same as those operating in DNA fragmentation, with the important exception of $5^{\prime}-\mathrm{P}-\mathrm{O}$ cleavage and water loss from the precursor. The more pronounced cleavage of the $3^{\prime}-\mathrm{C}-\mathrm{O}$ bond in DNA, compared with RNA, is most likely a result of three factors: (1) a dominating generation of $\mathrm{c}$ - and $\mathrm{y}$-ions in RNA fragmentation, which to some extend represses $3^{\prime}-\mathrm{C}-\mathrm{O}$ cleavage products; (2) as a result of more stable $\mathrm{N}$-glycosidic bonds in ribonucleotides, the generation of $(\mathrm{M}-\mathrm{B})$-ions, which are precursors of the (a-B)- and $\mathrm{w}$-ions, is less pronounced for RNA; (3) the reaction rate of the conversion of $(\mathrm{M}-\mathrm{B})$-ions into (a-B)- and $\mathrm{w}$-ions appears to be different, with a more rapid $\left[(\mathrm{MH}-\mathrm{B})^{+} \rightarrow(\mathrm{a}-\mathrm{B}) / \mathrm{w}\right]$ reaction for DNA than for RNA. This is caused by stabilization of phosphate-OH through interaction with $2^{\prime}-\mathrm{OH}$ on the $5^{\prime}$-neighboring ribose.

The $5^{\prime}-\mathrm{P}-\mathrm{O}$ cleavage and water loss from the precursor are unique reactions to RNA and, at least under the current ionization and fragmentation conditions, do not occur at all for DNA. Our H/DX data suggests a $5^{\prime}-\mathrm{P}-\mathrm{O}$ cleavage mechanism, which in some respects is similar to that taking place in solution. We propose that in the gas phase, an intermediate phosphorane is formed, which subsequently leads to either cleavage of $5^{\prime}-\mathrm{C}-\mathrm{O}$ or loss of a neutral water molecule. This is, in our view, the only explanation for the neutral loss of water, observed exclusively from RNA precursors.

\section{Acknowledgments}

The authors thank Thomas J. D. Jørgensen and Nicolai Bache for fruitful discussions and help with the instrumentation. They furthermore extend their appreciation to Novo Nordisk/Novozymes and The Siemens Foundation for generous support. 


\section{References}

1. Grotjahn, L.; Blocker, H.; Frank, R. Mass spectroscopic sequenceanalysis of oligonucleotides. Biomed. Mass Spectrom. 1985, 12, 514-524.

2. Grotjahn, L.; Frank, R.; Blocker, H. Ultrafast sequencing of oligodeoxyribonucleotides by FAB-mass spectrometry. Nucleic Acids Res. 1982, 10 4671-4678.

3. $\mathrm{Wu}, \mathrm{J}$.; McLuckey, S. A.; Gas-phase fragmentation of oligonucleotide ions. Int. J. Mass Spectrom. 2004, 237, 197-241.

4. Phillips, D. R.; McCloskey, J. A. A comprehensive study of the lowenergy collision-induced dissociation of dinucleoside monophosphates. Int. J. Mass Spectrom. Ion Processes 1993, 128, 61-82.

5. Gross, J.; Leisner, A.; Hillenkamp, F.; Hahner, S.; Karas, M.; Schafer, J.; Lutzenkirchen, F.; Nordhoff, E. Investigations of the metastable decay of DNA under ultraviolet matrix-assisted laser desorption/ionization conditions with post-source decay analysis and hydrogen/deuterium exchange. J. Am. Soc. Mass Spectrom. 1998, 9, 866-878.

6. Wan, K. X.; Gross, J.; Hillenkamp, F.; Gross, M. L. Fragmentation mechanisms of oligodeoxynucleotides studied by H/D exchange and electrospray ionization tandem mass spectrometry. J. Am. Soc. Mass Spectrom. 2001, 12, 193-205.

7. Gross, J.; Hillenkamp, F.; Wan K. X.; Gross, M. L. Metastable decay of negatively charged oligodeoxynucleotides analyzed with ultraviolet matrix-assisted laser desorption/ionization post-source decay and deuterium exchange. J. Am. Soc. Mass Spectrom. 2001, 12, 180-192.

8. McLuckey, S. A.; Habibi-Goudarzi, S. Decompositions of multiplycharged oligonucleotide anions. J. Am. Chem. Soc. 1993, 115, 1208512095

9. Wang, Z.; Wan, K. X.; Ramanathan, R.; Taylor, J. S.; Gross, M. L. Structure and fragmentation mechanisms of isomeric T-rich oligodeoxynucleotides: A comparison of four tandem mass spectrometric methods. J. Am. Soc. Mass Spectrom. 1998, 9, 683-691.

10. Kirpekar, F.; Krogh, T. N. RNA. fragmentation studied in a matrixassisted laser desorption/ionization tandem quadrupole/orthogonal time-of-flight mass spectrometer. Rapid Commun. Mass Spectrom. 2001, $15,8-14$.

11. Schürch, S.; Bernal-Mendez, E.; Leumann, C. J. Electrospray tandem mass spectrometry of mixed-sequence RNA/DNA oligonucleotides. J. Am. Soc. Mass Spectrom. 2002, 13, 936-945.

12. Tromp, J. M.; Schürch, S. Gas-phase dissociation of oligoribonucleotides and their analogues studied by electrospray ionization tandem mass spectrometry. I. Am. Soc. Mass Spectrom. 2005, 16, 1262-1268.

13. Chou, C. W.; Limbach, P. A.; Cole, R. B. Fragmentation pathway studies of oligonucleotides in matrix-assisted laser desorption/ionization mass spectrometry by charge tagging and H/D exchange. J. Am. Soc. Mass Spectrom. 2002, 13, 1407-1417.

14. Jørgensen, T. J. D.; Bache, N.; Roepstorff, P.; Gardsvoll, H.; Ploug, M. Collisional activation by MALDI tandem time-of-flight mass spectrometry induces intramolecular migration of amide hydrogens in protonated peptides. Mol. Cell. Proteom. 2005, 4, 1910-1919.
15. Cerny, R. L.; Tomer, K. B.; Gross, M. L.; Grotjahn, L. Fast atom bombardment combined with tandem mass spectrometry for determining structures of small oligonucleotides. Anal. Biochem. 1987, 165, 175-182.

16. Takagi, Y.; Warashina, M.; Stec, W. J.; Yoshinari, K.; Taira, K. Recent advances in the elucidation of the mechanisms of action of ribozymes. Nucleic Acids Res. 2001, 29, 1815-1834.

17. Cassano, A. G.; Anderson, V. E.; Harris, M. E.; Understanding the transition states of phosphodiester bond cleavage: insights from heavy atom isotope effects. Biopolymers 2004, 73, 110-129.

18. Horton, H. R.; Moran, L. A.; Ochs, R. S.; Rawn, J. D.; Scrimgeour, K. G. Principles of biochemistry, 3rd ed.; Prentice-Hall: 2002, pp 605-607.

19. Boschenok, J.; Sheil, M. M. Electrospray tandem mass spectrometry of nucleotides. Rapid Commun. Mass Spectrom. 1996, 10, 144-149.

20. Ni, J. S.; Mathews, M. A. A.; McCloskey, J. A. Collision-induced dissociation of polyprotonated oligonucleotides produced by electrospray ionization. Rapid Commun. Mass Spectrom. 1997, 11, 535-540.

21. Nordhoff, E.; Karas, M.; Cramer, R.; Hahner, S.; Hillenkamp, F.; Kirpekar, F.; Lezius, A.; Muth, J.; Meier, C.; Engels, J. W. Direct mass-spectrometric sequencing of low-picomole amounts of oligodeoxynucleotides with up to 21 bases by matrix-assisted laser-desorption ionization mass spectrometry. J. Mass Spectrom. 1995, 30, 99-112.

22. Nordhoff, E.; Cramer, R.; Karas, M.; Hillenkamp, F.; Kirpekar, F.; Kristiansen, K.; Roepstorff, P. Ion stability of nucleic acids in infrared matrix-assisted laser desorption/ionization mass spectrometry. Nucleic Acids Res. 1993, 21, 3347-3357.

23. Wang, B. H.; Hopkins, C. E.; Belenky, A. B.; Cohen, A. S. Sequencing of modified oligonucleotides using in-source fragmentation and delayed pulsed ion extraction matrix-assisted laser desorption ionization timeof-flight mass spectrometry. Int. J. Mass Spectrom. 1997, 169, 331-350.

24. Wan, K. X.; Gross, M. L.; Fragmentation mechanisms of oligodeoxynucleotides: effects of replacing phosphates with methylphosphonates and thymines with other bases in T-rich sequences. J. Am. Soc. Mass Spectrom. 2001, 12, 580-589.

25. Schneider, K.; Chait, B. T.; Matrix-assisted laser-desorption mass-spectrometry of homopolymer oligodeoxyribonucleotides-influence of base composition on the mass-spectrometric response. Org. Mass Spectrom. 1993, 28, 1353-1361.

26. Nordhoff, E.; Kirpekar, F.; Karas, M.; Cramer, R.; Hahner, S.; Hillenkamp, F.; Kristiansen, K.; Roepstroff, P.; Lezius, A. Comparison of IRand UV-matrix-assisted laser desorption/ionization mass spectrometry of oligodeoxynucleotides. Nucleic Acids Res. 1994, 22, 2460-2465.

27. Kirpekar, F.; Nordhoff, E.; Kristiansen, K.; Roepstorff, P.; Hahner, S.; Hillenkamp, F. 7-Deaza purine bases offer a higher ion stability in the analysis of DNA by matrix-assisted laser desorption/ionization mass spectrometry. Rapid Commun. Mass Spectrom. 1995, 9, 525-531.

28. Schneider, K.; Chait, B. T.; Increased stability of nucleic acids containing 7-deaza-guanosine and 7-deaza-adenosine may enable rapid DNA sequencing by matrix-assisted laser desorption mass spectrometry. Nucleic Acids Res. 1995, 23, 1570-1575. 